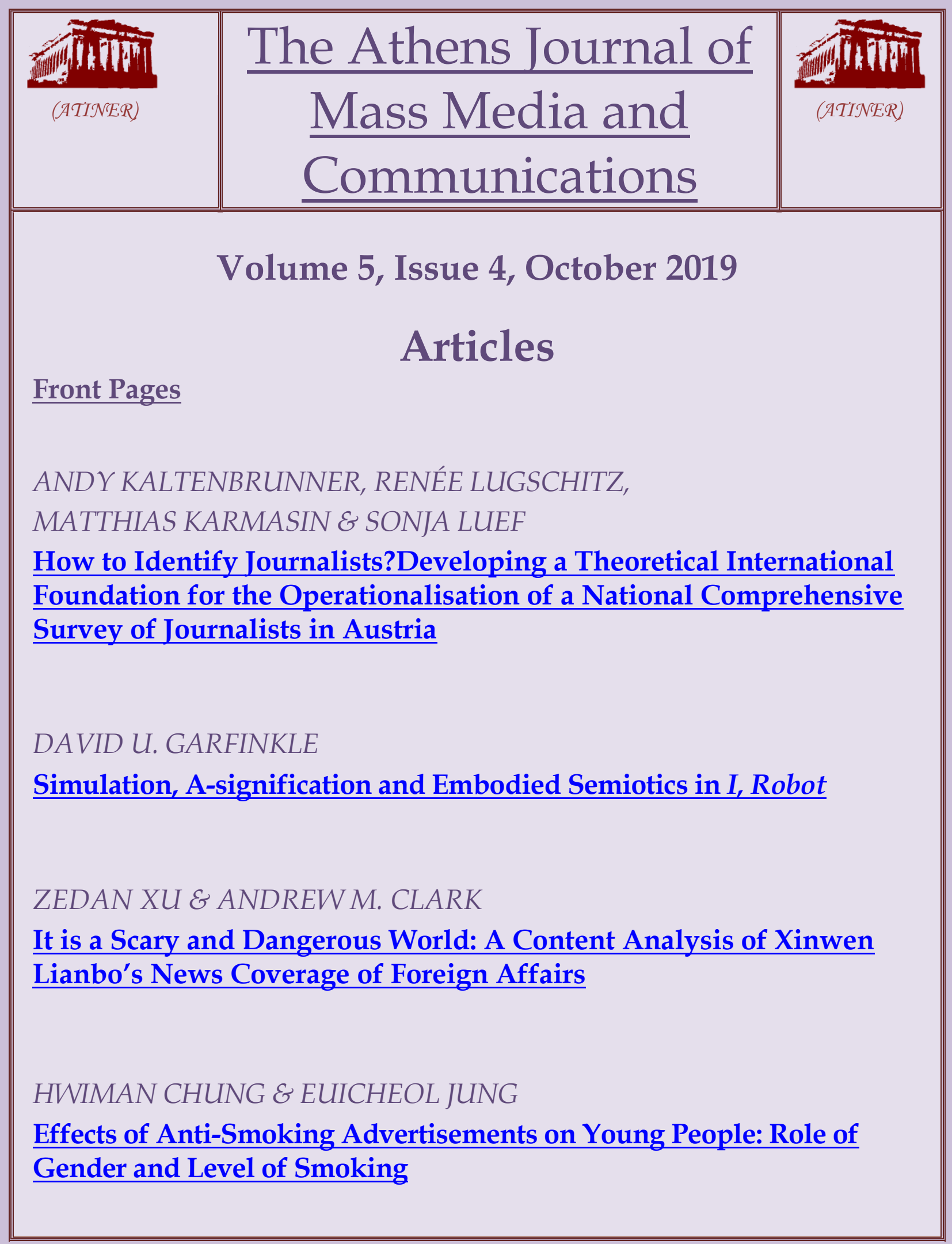




\section{Mission}

ATINER is a World Non-Profit Association of Academics and Researchers based in Athens. ATINER is an independent Association with a Mission to become a forum where Academics and Researchers from all over the world can meet in Athens, exchange ideas on their research and discuss future developments in their disciplines, as well as engage with professionals from other fields. Athens was chosen because of its long history of academic gatherings, which go back thousands of years to Plato's Academy and Aristotle's Lyceum. Both these historic places are within walking distance from ATINER's downtown offices. Since antiquity, Athens was an open city. In the words of Pericles, Athens"... is open to the world, we never expel a foreigner from learning or seeing". ("Pericles' Funeral Oration", in Thucydides, The History of the Peloponnesian War). It is ATINER's mission to revive the glory of Ancient Athens by inviting the World Academic Community to the city, to learn from each other in an environment of freedom and respect for other people's opinions and beliefs. After all, the free expression of one's opinion formed the basis for the development of democracy, and Athens was its cradle. As it turned out, the Golden Age of Athens was in fact, the Golden Age of the Western Civilization. Education and (Re)searching for the 'truth' are the pillars of any free (democratic) society. This is the reason why Education and Research are the two core words in ATINER's name. 
The Athens Journal of Mass Media and

Communications

ISSN NUMBER: 2407-9677 - DOI: 10.30958/ajmmc

Volume 5, Issue 4, October 2019

Download the entire issue ( $\underline{\mathrm{PDF}})$

Front Pages

How to Identify Journalists? Developing a Theoretical

233

International Foundation for the Operationalisation of

a National Comprehensive Survey of Journalists in

Austria

Andy Kaltenbrunner, Renée Lugschitz, Matthias Karmasin $\mathcal{E}$ Sonja Luef

Simulation, A-signification and Embodied Semiotics in

253

I, Robot

David U. Garfinkle

It is a Scary and Dangerous World: A Content Analysis 275 of Xinwen Lianbo's News Coverage of Foreign Affairs

Zedan Xu \& Andrew M. Clark

Effects of Anti-Smoking Advertisements on Young

People: Role of Gender and Level of Smoking

Hwiman Chung \& Euicheol Jung 


\section{The Athens Journal of Mass Media and Communications Editorial and Reviewers' Board}

$\underline{\text { Editors }}$

- Dr. John Pavlik, Head, Mass Media and Communication Unit, ATINER \& Professor, Journalism and Media Studies, School of Communication and Information, Rutgers University, USA.

- Dr. Yorgo Pasadeos, Director, Social Sciences Division, ATINER \& Professor Emeritus, University of Alabama USA.

- Dr. Patrick Vyncke, Professor of Communication Management, Department of Communication Sciences, Ghent University, Belgium.

\section{Editorial Board}

- Dr. John Pavlik, Head, Mass Media and Communication Unit, ATINER \& Professor, Rutgers University, USA.

- Dr. Burak Dogu, Academic Member, ATINER \& Vice Dean, Izmir University of Economics, Turkey.

- Dr. Andzela Armoniene, Head of The Fund Young Researcher, Lithuania.

- Dr. Mariam Gersamia, Professor \& Head, Division of Journalism and Mass Communication, Ivane Javakhishvili Tbilisi State University, Georgia.

- Dr. Egle Jaskuniene, Associate Professor \& Vice Dean for Research, Faculty of Creative Industries, Vilnius Gediminas Technical University, Lithuania.

- Dr. Berrin Yanikkaya, Academic Member, ATINER and Professor \& Head, School of Communication Studies, Auckland University of Technology, New Zealand.

- Dr. Dali Osepashvili, Professor, Department of Journalism and Mass Communication, Ivane Javakhishvili Tbilisi State University, Georgia.

- Dr. Walter Wymer, Academic Member, ATINER \& Professor of Marketing, University of Lethbridge, Canada.

- Dr. Alan Albarran, Academic Member, ATINER \& Professor, The University of North Texas, USA.

- Dr. Patricia L. Dooley, Elliott Distinguished Professor of Communication, Wichita State University, USA.

- Dr. Catherine Ann Collins, Professor, Department of Rhetoric, Willamette University, USA.

- Dr. Pamela Doyle Tran, Professor of Electronic News, University of Alabama, USA.

- Dr. S. Andrews, Professor, Department of Information Technology, Mahendra Engineering College, India.

- Dr. Emmanuel Ngwainmbi, Department of Communication Studies, The University of North Carolina, USA.

- Dr. Zsolt Alfred Polgar, Academic Member, ATINER \& Associate Professor, 
Technical University of Cluj-Napoca, Romania.

- Dr. Margaret M. Cassidy, Academic Member, ATINER \& Associate Professor, Adelphi University, USA.

- Dr. Baris Coban, Associate Professor, Communication Sciences Department, Dogus University, Turkey.

- Dr. Ulas Basar Gezgin, Associate Professor of Applied Communication, British University Vietnam, Vietnam.

- Dr. Anya Luscombe, Associate Professor and Head, Department of Academic Core, University College Roosevelt, The Netherlands.

- Dr. Charles Obot, Academic Member, ATINER \& Associate Professor, University of Uyo, Nigeria.

- Dr. Ceren Sozeri, Associate Professor, Faculty of Communication, Galatasaray University, Turkey.

- Dr. Matthew D. Matsaganis, Assistant Professor, Department of Communication, State University of New York (SUNY), USA.

- Dr. Geneviève A. Bonin, Assistant Professor, University of Ottawa, Canada.

- Dr. Klarissa Lueg, Assistant Professor, Aarhus University, Denmark.

- Dr. George Pavlou, Assistant Professor, European University, Cyprus.

- Dr. Yolandi Slabbert, Senior Lecturer, Department of Communication Science, University of South Africa, South Africa.

- Dr. Daniel Binns, Academic Member, ATINER \& Lecturer, RMIT University, Australia.

- Dr. Binoy Kampmark, Lecturer in Social Sciences, School of Global, Urban and Social Studies, RMIT University, Australia.

- Dr. Sarah Sparke, Academic Member, ATINER \& Research Associate, CMIR, University of the West of England, UK.

- Dr. Vittoria Sacco, Postdoctoral Assistant, Neuchatel University, Switzerland.

- Ms. Mania Alehpour, PhD Candidate, University of Tehran, Iran.

- General Managing Editor of all ATINER's Publications: Ms. Afrodete Papanikou

- ICT Managing Editor of all ATINER's Publications: Mr. Kostas Spyropoulos

- Managing Editor of this Journal: Ms. Zoi Charalampous (bio)

\section{Reviewers' Board}

Click Here 


\section{President's Message}

All ATINER's publications including the e-journals are open access without any costs (submission, processing, publishing, open access paid by authors, open access paid by readers etc) and are independent of the presentations made at any of the many small events (conferences, symposiums, forums, colloquiums, courses, roundtable discussions) organized by ATINER throughout the year. The intellectual property rights of the submitted papers remain with the author.

Before you submit, please make sure your paper meets some basic academic standards, which include proper English. Some articles will be selected from the numerous papers that have been presented at the various annual international academic conferences organized by the different divisions and units of the Athens Institute for Education and Research.

The plethora of papers presented every year will enable the editorial board of each journal to select the best ones, and in so doing, to produce a quality academic journal. In addition to papers presented, ATINER encourages the independent submission of papers to be evaluated for publication.

The current issue of the The Athens Journal of Mass Media and Communications (AJMMC) is the fourth issue of the fifth volume (2019). The reader will notice some changes compared with the previous issues, which I hope is an improvement.

Gregory T. Papanikos, President

Athens Institute for Education and Research 


\section{Athens Institute for Education and Research}

\section{A World Association of Academics and Researchers}

\section{$1^{\text {th }}$ Annual International Conference on Communication and Mass Media, 11-14}

May 2020, Athens, Greece

The Mass Media \& Communication Unit of ATINER organizes its $18^{\text {th }}$ Annual International Conference on Communication and Mass Media, 11-14 May 2020, Athens, Greece sponsored by the Athens Journal of Mass Media and Communications. The aim of the conference is to bring together academics and researchers of Communications, Mass Media and other related disciplines. Please submit a proposal using the form available (https://www.atiner.gr/2020/FORM-MED.doc).

- Abstract Submission: 8 October 2019

- Acceptance of Abstract: 4 Weeks after Submission

- Submission of Paper: 13 April 2020

\section{Academic Members Responsible for the Conference}

- Dr. John Pavlik, Head, Mass Media and Communication Research Unit, ATINER \& Professor, Rutgers University, USA.

- Dr. Yorgo Pasadeos, Director, Social Sciences Division, ATINER \& Professor Emeritus, University of Alabama USA.

\section{Social and Educational Program}

The Social Program Emphasizes the Educational Aspect of the Academic Meetings of Atiner.

- Greek Night Entertainment (This is the official dinner of the conference)

- Athens Sightseeing: Old and New-An Educational Urban Walk

- Social Dinner

- Mycenae Visit

- Exploration of the Aegean Islands

- Delphi Visit

- Ancient Corinth and Cape Sounion

\section{Conference Fees}

Conference fees vary from $400 €$ to $2000 €$ Details can be found at: https://www.atiner.gr/2019fees 


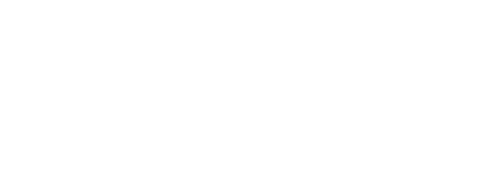




\title{
How to Identify Journalists? Developing a Theoretical International Foundation for the Operationalisation of a National Comprehensive Survey of Journalists in Austria ${ }^{1}$
}

\author{
By Andy Kaltenbrunner ${ }^{*}$, Renée Lugschitz ${ }^{\dagger}$, \\ Matthias Karmasin ${ }^{*}$ Sonja Luef ${ }^{\bullet}$
}

\begin{abstract}
A dozen years ago, journalists in several countries, the US, Germany, Switzerland, Austria and more, were precisely counted and socio-demographically analysed. Today there are no comparable current national surveys of journalism. For a recount of journalists - nation-wide in Austria we now have to re-define whom we are searching for. Yet, a clear assignment of who is actually a journalist is not merely necessary for noble research purposes, but also for very pragmatic reasons: Being a legitimate journalist accords prestige and credibility, gives access to information, funding, legal rights, and more institutionalised privileges. We assume that it is the protracted discussion emphasising the boundaries of journalism which complicates the reflection about the core of journalism and the identification of journalists. Accordingly, we considered it necessary to first re-think the nature of journalism, closely linked to international research, and to formulate the research questions very generally, in order to develop a basis for a comprehensive survey 2019 in Austria: What is journalism? What defines a journalist today? How can journalists be identifiedand then recorded? Answers will, ideally, not only serve as a starting point for the new survey of Austrian journalists but will also provide a basis for discussion of journalism researchers in other countries.
\end{abstract}

Keywords: Austrian journalism reports, comprehensive survey of journalists, definition of journalists, intercultural studies, quality of journalism.

\section{Introduction}

In the summer of 2018, Jay Rosen sent a letter to Germany's journalists, which was featured prominently in the Frankfurter Allgemeine Zeitung (Rosen, 2018). It was the result of three months of observations and 53 interviews focusing on the development of the profession and the growing insecurity felt by German journalists when practising their occupation. Almost immediately, German scholars and journalists voiced criticism of Rosen's letter, describing it as too "fuzzy" and "ambiguous" (see, e.g., Meier, 2018). Of equal, if not greater

\footnotetext{
*Director, Medienhaus Wien \& Institute for Comparative Media and Communication Studies Austrian Academy of Sciences, Senior Researcher, Austria.

${ }^{\dagger}$ Researcher, Austrian Academy of Sciences-Alpen-Adria-University Klagenfurt, Austria.

*Full Professor, Alpen-Adria-University Klagenfurt, \& Director, Institute for Comparative Media and Communication Studies-Austrian Academy of Sciences, Austria.

'Researcher, Austrian Academy of Sciences-Alpen-Adria-University Klagenfurt, Austria.

${ }^{1}$ This research is conducted within the scope of the project "Journalism in Transition", supported by the FWF Der Wissenschaftsfonds Project No. P 29614-G27, and jointly carried out by the Austrian Academy of Sciences/Alpen-Adria-Universität Klagenfurt and Medienhaus Wien.
} 
interest than the questions about self-conception in journalism - Rosen calls this "pressthink" - and about intercultural ambiguities, is the question that asks who such a letter, addressed "to the journalists", is ultimately directed at. Who is this, who makes up this group?

We have dealt with this question for the practical implementation of a comprehensive survey of journalists in Austria in 2019. For the first time such a field study was carried out more than 10 years ago. At that time, it was able to orient oneself on internationally comparable studies such as those conducted in Germany (Weischenberg, Loosen, \& Beuthner, 2006), the United States (Weaver, Beam, Brownlee, Voakes, \& Wilhoit, 2007), but also in smaller nations such as Switzerland (Marr, Wyss, Blum, \& Bonfadelli, 2001). In Austria a series of Journalism Reports (Kaltenbrunner, Karmasin, \& Kraus, 2010, 2013, 2017; Kaltenbrunner, Karmasin, Kraus, \& Zimmermann, 2007, 2008) established the transnational comparability of data on journalism.

We must acknowledge that even more than a decade ago definitional problems were already apparent. It was far from simple to narrow down and delineate the research topic in a precise manner. The "blurring boundaries" of journalism (Weischenberg, 2003) were already a prevailing issue in the international discourse. Settling on a clear definition proved challenging: "The borders, yet to be defined, between the journalism system and its surroundings are neither distinct nor 'natural'; they have to be constructed" (Kaltenbrunner et al., 2007, p. 161).

The trends, which became apparent a dozen and more years ago, have since wrought a radical transformation of public communications - and also seem to have unsettled journalism research: Attempts to find more recent international comprehensive surveys about journalists in various countries and media cultures that have been defined along similar lines (Hallin \& Mancini, 2004), in order to learn and to achieve comparability, is currently doomed to fail. According to our current knowledge, no new studies have been published claiming such aspiration for a complete sociodemographic overview of a country for more than a decade.

Certainly, extensive and highly differentiated literature and works from theory and practice do exist concerning the developments in the media landscape, which address social media and other new, digitally effective protagonists.

However, as mentioned above, our research observations reveal that there are no up-to-date comprehensive surveys of journalism as a profession at the respective national level giving guidelines for such a clearly defined basic population useful in an international context. At the same time, the debate about the boundaries of journalism has gained constantly in intensity during the last decade. We assume that it is precisely this protracted discussion concerning the differentiation between PR, public engagement, advertising, citizen journalism, and journalism - often also referred to as professional, real, or quality journalism which complicates the reflection about the actual nature of journalism. In many cases, we primarily consider the boundaries, rather than the core of journalism. The question is the same as one decade ago: Who - in an era of citizen journalists, bloggers, and audience engagement experts - is still a genuine journalist? Consensus remains elusive. 
Not even Kovach and Rosenstiel (2014, p. 7) focusing on the "elements of journalism" offer a concrete starting point. On the contrary: "While once...the word journalist described a group of organized professionals...now it describes anyone who might find him or herself producing news and who aspires to do it ethically and responsibly". How to find and how to count them with such vague coordinates?

The paper at hand does not presume to seek out the absolute and ultimately valid answer about the nature of journalism. However, our recent research requires a workable definition for the pragmatic operationalizability of an advanced study that comprises all of Austria's journalists. This new comprehensive survey of journalists in Austria 2019 is designed to allow a meaningful data comparison, simultaneously revealing in greater detail the evident, profound changes of the profession. More than 300 media companies in Austria are examined. In a first step, journalists are recorded following the definition developed here. This is done in different ways: Firstly, questionnaires with according criteria are sent to all media companies. Secondly, interviews are conducted with CEOs, human resources managers and other media managers from larger media companies. Thirdly, data from existing lists, for example the media handbook of the VÖZ (Association of Austrian Newspapers) as well as information on editorial members of the media themselves (in particular on websites) are checked and registered. This general survey will provide socio-demographic data such as number, gender, age, income, academic degree of Austrian journalists. In a second step, in-depth interviews (CATI) will be conducted with 500 Austrian journalists on topics such as role models and self-image, political self-assessment, changes in everyday working life, workload and job satisfaction.

The definition developed here will, ideally, not only serve as a fundamental starting point for our survey in Austria but also as a useful base of discussion for comprehensive surveys in other countries, following adaptation to the respective national specific requirements.

It might help to bring the discussion about the characteristics of journalism back to where it belongs. Interestingly, the vigorous debate on the topic is currently "driven by practitioners, pundits, and scientists from other fields. Journalism studies, on the other hand, seems largely absent", as Nielsen (2018) states after following the vivid discussions at the Perugia Journalism Festival in spring 2018. Accordingly, we formulate the questions in a general manner:

- What is journalism?

- What defines a journalist today?

- How can journalists be identified and recorded?

Given the historical context, our initial hypothesis is optimistic. It must be possible to concretize the term journalism. After all, journalism, its structures and framework conditions have already been through changes in the past. Even the question about its boundaries was previously raised prior to the twenty first century: "Who truly is a journalist?" - was the subject of a debate as long ago as the Third German Journalists' Day in Berlin in 1868. As they stated: "If we want 
to include everyone who has ever published a few articles or correspondences in journals, then this number will be quite unlimited..." (quoted in Requate, 1995, p. 131).

More than 150 years later we approach and discuss this problem by starting with an overview of the most important current debates regarding journalism. In the main part we deal with the question "What is journalism" and work out a definition: Firstly, an outline describes the problem, also from a historical perspective. Subsequently, we present fundamental ideas of international research on task and nature of journalism and contrast this with the specific situation in Austria. We identify and discuss different levels for determining journalism: its democratic-political task; indispensable principles of practice; occupational and organisational nature. As a result of the discussion, a definition of journalism is developed, which on the one hand will serve as a starting point and manual for a complete survey among Austrian journalists and on the other hand shall provide a basis for discussion for comparable studies in other countries.

\section{Literature Review}

An increasing number of studies deals with the distinction of journalism from other forms of public communication or the characteristics of journalists as opposed to other protagonists in the media-related public sphere (see e.g., Carlson \& Lewis, 2015a; Grubenmann \& Meckel, 2015; Neuberger, 2017; Örnebring, 2013; Shapiro, 2014; Young \& Carson, 2017), while others are concerned with the determination and measurement of quality in journalism (García-Avilés, CarvajalPrieto, Lara-Gonzalez, \& Arias-Robles, 2016; Gertler, 2013; Lacy \& Rosenstiel, 2015; Weischenberg et al., 2006), and yet other significant research efforts tackle issues surrounding production, organisation, digital transformation and management (Küng, 2015; Wyss \& Keel, 2016; Kaltenbrunner, 2017).

Furthermore, there are comparative studies for various countries, such as, in particular, the Worlds of Journalism studies, which also integrate surveys conducted in Austria (see, e.g., Lohmann \& Seethaler, 2016; Seethaler, 2017). These studies, which have gained broad recognition due to their extensive international scope, permit highly diverse concepts of journalism in each of the 67 countries. "Journalism culture is taken as the starting point of comparison, because culture itself is a process of continuous change, renegotiation and redefinition" (Hanitzsch et al., 2011).

Some definitional vagueness and "cultural" flexibility in this regard facilitates comparative studies from Albania via China and Sierra Leone to the US. Naturally, it puts comparability into perspective, particularly in those countries, where no national surveys employing transparent terms are available, defining who, precisely, the journalists are, who should be interviewed - and who should not. 


\section{Methodology}

The development of an international standard-compliant theoretical foundation for a complete survey of Austrian journalists is based on two qualitative approaches:

(a) Extensive literature research: Analysis and discussion of international literature, both current research work and older standard works dealing with the nature of journalism and its differentiation from similar forms of communication. Comparative discussion of recent research with international researchers coming from different media-cultures (e.g., US, UK, Germany, Switzerland, Spain). From this, the main lines of different international concepts of journalism were filtered out.

(b)Field research: The theoretical approaches found in international literature were juxtaposed with our findings about Austrian practice in journalism. The necessary knowledge of data/characteristics of the Austrian practice are based on various preliminary studies and debates with practitioners.

- Interviews with 120 local and regional journalists from print, radio, TV and online-media on their work situation in the digital era.

- Listing of 16 theses on "What is Journalism?" in cooperation with the "Forum Journalismus und Medien" (Fjum and Medienhaus Wien, 2017), an Austrian training academy for journalists. Those 16 assumptions were also discussed with journalists in the traditional Austrian press club Concordia and with the readers and users of the Austrian daily newspaper Der Standard (Austria's largest online community) ${ }^{2}$.

- A nationwide study based on qualitative interviews with editors in chief and managers in all 14 Austrian newspapers in 2016/2017 gave an overview of digital developments and integration-processes in the newsrooms and changes in professional attitudes.

Results of the studies were summarised (Kaltenbrunner et al., 2017) and delivered to all the participants and discussed at the Global Editors Network summit 2017, where 800 editors from all continents had assembled.

\section{What is Journalism?}

\section{Starting Point: An Open Profession in Search of its Borders}

In most western countries Journalism has always been an open profession. Although training and continuing education for journalists has become established in Europe after World War II, often following US examples, at universities,

\footnotetext{
${ }^{2}$ See, e.g., https://ces.to/DglqiO.
} 
universities of applied sciences, and in vocational training institutions, no formal or legal provisions exist that might limit access. This is a marked contrast to academic careers such as those in the fields of medicine and law, or to technical professional qualifications, such as training to become an electrician. "Anyone who wishes to do so can call themselves a journalist. The job title is not protected; there is no prescribed job profile, no minimum qualification requirements, nothing", Hooffacker and Meier (2017, p. 1) observe generally in relation to the German-speaking world.

One of the few exceptions in Europe, where access to the profession is tied to formal criteria, is Italy. Here, only those who are registered with the professional chamber are considered to be journalists, and this requires the completion of an 18-month internship or of a recognised journalism college or respectively, a relevant university degree.

In Austria, our field of research for a new national survey, only some rough framework and definition of journalism is given in an almost one century old "Journalistengesetz", approved in 1920. This early law, worded after monarchy, war and centuries of censorship embraced the idea of journalism without restraints and without formal obligation for membership in chambers, unions or similar organisational bodies (Kaltenbrunner et al., 2007, p. 11).

Open access as in Austria or in the US, in Germany or in Scandinavia was also one of journalism's historic qualities. The freedom of the press in Europe and the USA evolved, according to George, to protect the "bloggers" of the early days of journalism: "the partisans, the ideologues, the lone pamphleteers" - individuals, who were not backed by a political lobby ("Who is a journalist?", 2008, p. 129). They did not know any professional ethics codes and they had no journalistic training. The claim to independence and objectivity only developed fully over time and these were not significant at first.

In America, journalistic standards were first officially set out in 1923: It was then that the American Society of Newspaper Editors published its Code of Ethics. "The key terms were factuality, independence, impartiality, and public service" (Kaplan, n.d., p. 34). Then, too, the classic media felt unsettled by new protagonists in the public communications sphere and attempted to dissociate themselves from the up-and-coming public relations industry by means of such quality standards: American journalists "felt a need to close ranks and assert their collective integrity in the face of their close encounter with the publicity agents' unembarrassed effort to use information (or misinformation) to promote special interests" (Schudson, 2008, p. 298).

Even so, formal, legal access barriers were never implemented. For many decades, this individual, open access to the profession, unencumbered by regulations, was upheld by the protagonists themselves; the free, informal character and the diversity of journalists were defended as innate principles. Now it seems that competition in the digital era is increasingly causing long-serving journalists to close ranks. Evaluating a survey of journalists in six European countries, Örnebring (2013) discerns a marked emphasis of the collective character of journalism, which he regards as a result of the digital upheavals. This is not merely to be understood as a distinction from citizen journalists, whose 
individuality and whose lack of institutional ties is considered problematic. This is also contrary to the traditional view of journalism with its pronounced claim to "individual freedom" and "individuality of expression" (Örnebring, 2013, p. 48).

However, this new self-conception also fails to offer a consistent definition as to what, precisely, journalism is. Shapiro justifies his study on Why democracies need a Functional Definition of Journalism now more than ever with the great discordance among practitioners as well as scholars concerning the nature of journalism. In doing so, he refers to Zelizer, who recognized, in the year 2004, that journalism was in the process of becoming "a whole of various contradictory parts". Even "key definitional issues" such as the occupational nature, are contested, according to Shapiro (2014, p. 555).

What is more, however: The challenging debate about true journalism often misses the actual issue or, rather, the definition is confused with an evaluation. Discussions frequently revolve around good or bad journalism, even before there is agreement on what actually defines journalism: "The differentiation between quality journalism and journalism is an avoidance strategy, as it blocks out the question of what deserves to carry the label journalism, and what does not. People speak about quality journalism in order to avoid talking about journalism" (Arlt \& Storz, 2016, p. 11; see also Shapiro, 2014). Furthermore, the image of journalists as an occupational category is poorly regarded in almost all European countries. One of the more recent surveys, for example, conducted in 2013 by the Spanish Centro de Investigaciones Sociológicas (CIS), notes: "Journalists are the occupational group that is least regarded by the Spanish, with only 59.09 points on a scale that ranges from 0 to 100" (García-Avilés, 2015, p. 215). In addition, the image ratings have continued to decline at a low level in many countries for some time now. This low esteem is exploited by politicians and spin doctors, who systematically disparage well-informed but uncomfortable journalism as fake news, and libel journalists as participants in a mendacious press.

This powerful societal headwind is one reason why quality journalism is a particularly fiercely discussed topic today, but in terms of research, it already started to shift into the focus of scientists' interest in the early 1990s. Denis McQuail (1992) was among the first to address the issue of quality in journalism. His normative approach focused on the "public interest", which journalism was supposed to serve. The Dutch scholar Irene Meijer-Costera (2001) also developed a "normative framework". In the German-speaking area, Stephan Ruß-Mohl (1994a), in particular, was one of the first to look at quality in journalism. In his view, quality depends in the first instance on the production process and the infrastructure. He considers it to be dynamic and changeable, and calls for an understanding of the "multiplicity of qualities" (Ruß-Mohl, 1992, 1994a, 1994b; see also Gerard-Wenzel, 2017).

The discussion, which has since been held at various levels, attempts to reason how quality in journalism can emerge and persist under economic pressure (e.g., Karmasin, 1996), how this quality can and should be measured (e.g., Bucher, 2003), develops appropriate criteria in the 1990s (e.g., Göpfert, 1993), uses quantitative and qualitative content analyses in specific fields of media to measure (e.g., McLachlan \& Golding, 2000), and asks how quality criteria can be applied 
in new, digital fields, in online journalism, after the turn of the millennium (García-Avilés et al., 2016; Quandt, 2004).

And yet, we can only determine how good or how bad journalism is, once it is clear what journalism is. It is essential to heed this distinction. For, all too often, that which carries the label of "journalism" does not contain journalism - and this trend is set to continue, as the Swiss Media Commission surmises, which has also addressed the issues of subsidising media and journalism from a practical perspective: "Already today and especially in the future, however, there are a variety of alternative forms of content generation and dissemination that are similar to and compete with professionally run journalism" (EMEK, 2017, p. 13). In its 2017 position paper, EMEK argued for a clear separation. After all: public engagement, native advertising, corporate publishing, content marketing, citizen journalism, entertainment, blogs - many want to partake in the image of journalism without adhering to its standards. That is not bad journalism, but rather it is not journalism at all.

An unambiguous attribution is not merely necessary for noble research purposes, but also for very pragmatic reasons: "Definitions matter, because how we think about the issue of boundaries has real consequences. [...] Being deemed a 'legitimate' journalist accords prestige and credibility, but also access to news sources, audiences, funding, legal rights, and other institutionalized perquisites" (Carlson \& Lewis, 2015b). In the research field of Austria, where we specify and measure journalism, this privilege has a long-standing tradition: In order to protect their sources, journalists are allowed to invoke the reporter's privilege, the socalled "Redaktionsgeheimnis". Press credentials are issued at the suggestion of the owners' associations and the journalists' union and are endorsed by the Ministry of the Interior. This is designed to help with investigations, including research conducted at public agencies. A number of special tax regulations apply individually for journalists. To identify such journalists in Austria, we have to ask: What is actually journalism?

\section{International Approaches to the Search for Identity}

The transformative changes brought about by digitization have been a dominant topic in journalism research for years, and the discussion about quality is a part thereof. The characteristics of the new journalist, the new protagonists, and the latest trends in the media world are currently being sought in Australia as well as in the US or Europe (see, e.g., Young \& Carson, 2017; Grubenmann \& Meckel, 2015; Meyen \& Riesmeyer, 2012). This permanent and fast transformation of journalism has attracted research interest from many perspectives, including media management (Killebrew, 2005; Dal Zotto \& van Kranenburg, 2008), emerging business models (Carvajal, García-Avilés, \& Gonzalez, 2012; Nee, 2013), interactive technologies (Gynnild, 2014), the new relationships with active audiences and social media (Singer et al., 2011), and media innovation (Storsul \& Krumsvik, 2013), to name only a few. We try to understand it with all its manifold consequences for journalism: "The convergence of legacy and online media: a challenging scenario" (García-Avilés, Meier, \& Kaltenbrunner, 2017). 
Unanimity is limited, strictly speaking, to this: Change never ends. "The only clear conclusion is that boundaries will continue to be drawn, erased, and redrawn" (Carlson \& Lewis, 2015b). Accompanying and studying this process in public communication represents a complex challenge, because digital disruption and constant change in daily life are naturally a step ahead of research and the traditional media. This makes a basis, a reference - something akin to an immovable rock amidst the digital surge - all the more necessary, should it exist. After all, other structures, new stakeholders, digital workflows, do not have to imply that journalism itself must receive a new meaning. Similarly, Kovach and Rosenstiel (2014, p. 16) also follow this line of argument: "The purpose of journalism is defined not by technology, nor by journalists or the techniques they employ, but by something more basic: the function news plays in the lives of people".

Put in the form of questions: What significance does the transformation in practice have for the theory? Do new technical possibilities and working methods require a re-definition of journalism itself? What, in fact, are the function and characteristics of journalism?

Level 1: The democratic approach. At their core, the definitions of journalism and of its purpose postulated by social science feature a common basic understanding of the same as a service provider for a democratic public.

A comprehensive description of the nature and the mission of journalism, which may serve as a point of departure here, is provided by Meier in his German standard work and introduction to Journalism:

Journalism investigates, selects and presents topics that are new, factual and relevant. It establishes publicity by observing society, providing this observation to a mass audience through periodic media and thus constructing a common effect. This constructed reality offers orientation in a complex world (Meier, 2007, p. 13).

English-language studies also place the regular presentation and conveyance of new and significant topics, which allow democratic debate within society, at the centre of their definitions: "[T]he purpose of journalism is to provide people with the information they need to be free and self-governing" (Kovach \& Rosenstiel, 2014 , p. 9). We can keep it short and simple, as journalists would do: To regularly provide relevant, truthful information, as an aid to orientation for citizens in a society - that is the mission of journalism, at least in Western-style democracies like our research country Austria.

However, that alone does not suffice for the differentiation from other types of public communication. A political party, a pharmaceutical company might regularly publish news from their fields of interest, as a newspaper, on online platforms or as a newsletter, where they not only use PR slogans for advertising purposes, but also report facts and figures. Nonetheless, that is not journalism. To verify whether an information product does indeed represent journalism, there consequently also has to be a second level, namely that of the theoretical principles, the core values or core elements, on which journalistic practice is 
based, and by the application of which it can fulfil its democratic responsibility. Which principles are these?

Level 2: The principles of practice. The multiple attempts of international researchers to define these journalistic virtues usually lie quite close to one another and have remained the same for decades. For instance, Deuze, referring to earlier works in the English-language realm by Golding and Elliott as well as Merritt, summarised these virtues as follows: public service, objectivity, autonomy, immediacy, ethics (Deuze, 2005, pp. 446-447). Similar "broadly valid values" apply in the German speaking countries Switzerland, Germany and Austria: "Unabhängigkeit, Überparteilichkeit, Aktualität, Relevanz, Richtigkeit, Kontrolle, Allgemeinverständlichkeit" (Arlt \& Storz, 2016, p. 13; Dernbach, 2017).

The values are formulated as the set of characteristics of journalistic practice which are indispensable. These properties must be understood as ideal-typical; they are never met entirely, but the commitment to do so must be given.

The terms can vary, there might be a distinction between impartiality, objectivity, neutrality, or balance, or the general comprehensibility might be understood as good "narration" (Wyss \& Keel, 2016). Other scholars such as Kovach and Rosenstiel (2014) warn against the use of terms such as fairness, balance, or objectivity on account of their arbitrary nature or their dubious benefits. They call for: truth, loyalty to citizens, verification, independence, monitor of power, public forum, relevance, comprehensiveness, responsibility. In principle, however, despite varying nuances, these terms form a basis, about which there is largely an international consensus.

Researchers who regard journalism as a functional system tend to lean primarily on the actions associated with these virtues, in order to derive a functional definition: "Journalism comprises the activities involved in an independent pursuit of accurate information about current or recent events and its original presentation for public edification" (Shapiro, 2014, p. 561). The occupational nature of journalism is not a prerequisite here (see, e.g., Wyss \& Keel, 2016; Shapiro, 2014).

According to the general consensus, the practice of journalism involves working stages such as "investigation, verification, selection and curation of information, its processing and dissemination" (EMEK, 2017, pp. 12-13). However, in regard to these practice-related definitions, the contextual connection with the virtues and the explicit reference to the democratic claim is always essential. If this connection is not adequately established, the concept of journalism becomes blurred. Dernbach, for instance, derives the following definition from the system-theoretical literature: "Journalists collect, process, and publish current and relevant topics (usually arranged into editorial structures and on the basis of specific action programmes [...], which they make available to the public via media" (Dernbach, 2017, p. 1). Without an additional explanation of the "action programmes" or a detailed specification of the "media" concerned, this does not permit journalism to be differentiated from public relations and other forms of communication. 
We believe that new professional titles, namely PR Journalist as suggested for example by Dernbach (2017), should not simply be attributed to the increasingly heterogeneous occupational field of journalism. At best, they belong to the much wider area of public communication which, in turn, is divided into specific subsections such as PR or journalism, and which must accordingly be considered in a differentiated manner. In our opinion, the term PR Journalist is an oxymoron, which suggests that public relations could also be a form of journalism. Thus, it would be best to avoid this term entirely.

The digital revolution has definitely transformed the structures, techniques, working processes, and possibilities of public communication, including those pertaining to journalism. Lohmann and Seethaler (2016, p. 5) state for Austria: "Journalism is currently in a state of change. According to Austrian journalists, the importance of the use of search engines and technical skills had most profoundly changed over the last five years". However, this transformation does not refer to the theoretical basis, neither in Austria, nor internationally: The nature of journalism has remained the same.

Journalism can be disseminated across various media channels - on online platforms just as in traditional newspapers - it can be practised in a variety of business models and organisational forms - independently or as an employee of an editorial office in a traditional media company, in an autonomous editorial office or, if need be, as a lone blogger - as long as certain conditions are met.

In order to ascertain whether we are dealing with journalism, it is necessary to conduct investigations on two levels that are separate but based on one another. These are the two steady rocks we perceive in the digital surge, when we ask who it is that practices journalism:

1. Democratic claim: Does the medium/staff feel committed to the societal mission to regularly provide information as a guide to orientation in the public and democratic discourse of a society?

2. Behaviours of the protagonists: In the practical setting, does the medium/staff feel obliged to the principles of autonomy, impartiality, immediacy, relevance, veracity, control, and general comprehensibility?

Autonomy as a fundamental unique feature. The detailed depiction of the meaning, distinctions, and development of the individual concepts as well as the associated variety of interpretations and discussions - as they apply to the term "objectivity", for instance (see, e.g., Schudson 2008; Tuchman, 1972; Bentele, 2008; Sponholz, 2009; Kaplan, n.d.; Lane, 2001) - goes beyond the scope of this work. However, in view of the objective of our research endeavour - establishing unambiguous criteria for the comprehensive survey of all journalists in Austria one of the continuously cited features of journalistic uniqueness seems to us to be crucial and verifiable in research practice: independence or autonomy. This, too, was already discussed in newspaper studies almost a century ago. Bücher (1926), for instance, called for "independence and incorruptibility" in reporting and denounced the pressure exerted on the press by politics (Bücher, 1926, pp. 32, 37). 
To date, research cites this as the fundamental characteristic: "Autonomy is the central feature for the distinction of descriptions of reality that are either journalistic or alien to journalism, in the sense of independence from individual communication interests, as they tend to be expressed in campaigns, public relations, content marketing, or advertising" (Wyss \& Keel, 2016, p. 3). After all, the argument goes, all other forms of communication can also produce their contents by using the tools of the journalistic craft - thus relaying current, relevant information to their audience in a regular and truthful manner. And yet, the selection and presentation of this information is subject to the individual interests of their owner or purely for the purpose of entertaining the audience, and not for the benefit of a democratic, pluralistic public.

The explicit meaning is this: A medium that orients itself along the interests of a public body, a party, an institution, a tourism association, a private enterprise, etc. - that practices Umfeldberichterstattung (ambience reporting), as it is called in Austrian and German journalism analysis - cannot be regarded as a journalistic institution, and likewise its staff are not journalists, however much they adhere to other rules of the journalistic craft. In practice, this distinction can often raise difficulties in individual cases. Let us again give examples from Austria which might well serve as transfer picture for questions raised in many countries: If a parish publishes a church newspaper, according to our understanding, this can be several different things: information for members, public relations, organisational communication, or even corporate publishing. By our reckoning, it is not independent journalism. Yet, there are dozens of that kind of media in our research field. On the other hand: If a medium that is owned by a church or a religious community commits itself to independent reporting in its editorial statutes or in a mission statement, if the editors are independent journalists and not functionaries within the church, then at first glance - presumably - journalists are at work here. Austria is suited particularly well to illustrate this point, with its long-standing tradition of so-called Katholische Press-Vereine (Catholic press associations) serving as one of the sturdiest pillars of the media landscape: The national, Catholic press agency kathpress is - and this is also stated in the imprint - an "ecclesiastical institution" (https://www.kathpress.at/site/impressum), the publisher is simultane-ously an Austrian cardinal and media bishop. This is no independent medium, and consequently, this is not journalism. For our survey this means that we do not include employees of this press agency.

The situation is different in the case of the Catholic Styria Mediengruppe, which is the third largest media company in Austria and belongs to a Catholic media foundation. There, two large daily newspapers, several magazines, broadcasting corporations, and a number of journalistically motivated online portals alongside the exclusively commercially oriented kind, are shaped by journalistic editorial offices, with no direct dependence on churches (https://www.styria.com/ de/impressum/). In line with our definitional approach for our survey, we consider the staff members working there to be journalists.

We can also detect various forms of (in)dependence of journalists in Austria in the fastest growing media company with one of the best-known international brand names: The beverage producer Red Bull is the proprietor of a national TV 
station and a large facility for international TV-, movie- and crossmediaproduction with a focus on sports, which describes itself as part of and committed to "the brand world of Red Bull". The corporation also produces an elaborate lifestyle "bulletin", an obvious corporate publishing product with massive printruns in the German-speaking world, which is regularly added to independent newspapers as an enclosure against payment. Both often include well-done reportages, good pictures, interesting topics - yet we see this as a part of corporate publishing. We do not count its content producers as autonomous journalists.

Red Bull's media company also publishes leisure magazines with strong links to nature, where the "ambience journalism" is a priori less obviously perceptible. But lines are blurring: The CEO of Red Bull has launched Addendum, an "investigative" online platform, within what he terms a "fully independent" foundation framework. Here, dozens of employees investigate topics ranging from international migration to criminal law or social policy. They depend on the foundation's further financing of their work - but explicitly feel obliged to do journalism with autonomy and without any concessions to the Red Bull corporate interest.

The complexity and difficulty of differentiation is obvious in most western countries, given strong competition for traditional journalistic legacy media under the framework of globalisation and digitalisation: So called "branded content", paid by third parties, has become part of many channels. In surveys for the "New Worlds of Journalism" the journalists in Austria - and similar in neighbouring Germany - describe how "profit making pressure" has strengthened a lot throughout the last years (Seethaler, 2017, p. 55). For our national research we therefore argue that while seeing media as composita mixta of cultural and business interest we have to look even closer, where and how journalism is affected in its independence and autonomy by growing economic pressure.

Level 3: The Question of Occupational Nature. Can only those practise journalism, whose occupation - and living - is tied to this field? The answer to this question is not only highly contentious in practice, among bloggers, professional journalists, and citizen journalists, but also in the theoretical and academic discussion. Taking the system-theoretical perspective, Wyss and Keel in Switzerland believe that "the occupational nature of journalism is no longer selfevident". In their view, "today, the consensus largely prevails that journalism, on the one hand, can no (longer) solely be defined through the job or the profession, and on the other hand, it cannot solely be defined as the activity of producing journalistic performance in editorial offices or media organisations" (Wyss \& Keel, 2016, p. 2).

For many years the contrary attitude of the Austrian journalism researcher Hummel can be seen on the website of the Austrian training institution KfJ: "Anyone who, as a citizen, exercises his right to freedom of expression via various media - from the magazine to the Internet - in his spare time, fulfils an important social task in doing so and may even be partially supported by the public sector via press subsidies. But only if one can live from this activity, is it journalism" (Hummel, n.d.). We still share this belief that journalism is a profession. The 
occupational nature is also a precondition for our survey. However, this point of view is not merely the result of formal and research-pragmatic reasons, in an attempt to keep the number of Austria's journalists manageable. It seems important to us - in theory and in practice - to unambiguously endow this open occupation with its disputed boundaries the definition of a profession.

Our perception of the current market situation in Europe and beyond tells us that it is becoming more difficult to earn one's livelihood as a journalist. The wage and fee level in legacy media is dropping in many countries. Generally speaking, it must also be noted that journalists working in the new, digital media, be they freelance or employed, tend to earn less than their colleagues in the traditional media. On the other hand, there is an increasing demand for digital qualifications. Technical skills and production across various channels are prerequisites even for jobs in small local and regional media, as current industry surveys illustrate in Europe (see, e.g., Luef \& Kaltenbrunner, 2018) and the US (Radcliffe, Ali, \& Donald, 2017), which investigate digital professionalisation in small-market newspapers.

Those required to achieve all of this must have received training - vocational training - that qualifies her/him accordingly, and must also be subject to a professional, industry-specific form of control that monitors the careful handling of journalists' rights and obligations. This core value of control is set to gain importance in the future, if it is to aid the distinction from all media production similar to journalism, which is not journalism. One of the biggest communications science EU projects of recent years placed "journalists and media accountability" (see, e.g., Fengler, Eberwein, Mazzoleni, Porlezza, \& Ruß-Mohl, 2014, Eberwein, Fengler, \& Karmasin, 2018) at the centre of comparative efforts in 14 countries.

The demands for journalistic responsibility, qualification, accountability, and self-regulation can only be met by the occupational profile of journalism. Thus, the occupational nature - following the democratic mission and the commitment to the journalistic principles - is the third level to serve as a prerequisite for our understanding of journalism.

The Question of Organisational Nature. In terms of system theory, journalism is usually regarded as a socially indispensable function, which can, as a general principle, be carried out by any citizen. Thus, the practice of journalism is not "exclusively linked to the organisational framework of mass media", but rather it can "also be contemplated beyond the boundaries of traditional media organisations" (Wyss \& Keel, 2016, p. 1). Even if the occupational nature is defined as a prerequisite, this does not necessarily entail an automatic linkage to an organisation.

This is apparent when we consider the developments of recent years. New investigative data journalism, in particular, which has become established through the digital possibilities, is often performed in smaller, newly founded editorial offices. These use various channels for publication purposes, such as digital platforms, but also traditional mass media. Similarly, it is logical to argue that bloggers or YouTubers who are active on the basis of the three previously described levels which shape journalism should also be classified as journalists. 
Whether they actually meet these criteria in practice can only be verified in the respective individual case.

Without a doubt, for an individual without institutional ties, without the valuable support and exchange available from editorial desks or offices (which are accessible, albeit in a limited fashion, even to freelancers), or without journalist associations, it is difficult to safeguard the adherence to journalistic principles as well as to ensure an income. However, it is not impossible. In our opinion, institutional integration is therefore not a prerequisite, but it is a significant advantage for doing journalism.

\section{Conclusions and Definition as a Starting Point for the 2018/2019 Comprehensive Survey}

Let us glance back to the starting point of our research considerations: In view of sweeping changes in public communications and in the media industry, it made sense to review the criteria that were applied in several European countries and the US for the purpose of identifying, counting and socio-demographically analysing journalists more than a decade ago. This required us to pose the question "What defines a journalist?" anew.

Our assessment criteria for counting journalists in a given country should not only be retrospectively transparent, but from the outset it should be comparatively integrated into the international discourse with a clear research perspective and it should be meaningful for practitioners as well. For this purpose, the work was and is - as is the case in the paper at hand - continuously presented to and discussed with critical members from among the ranks of journalism researchers, as well as journalists and media producers themselves.

We have now defined three levels for the purpose of our survey, upon which journalism is based, and where journalism can be distinguished from other forms of communication. These are:

1. Journalism as a service provider for democracy: There must be a claim to ensure the free formation of opinion in a society by providing information.

2. Journalism as an obligation to comply with journalistic principles: We see these as independence/autonomy, impartiality as no one-sidedness, immediacy, relevance, veracity, control, general comprehensibility.

3. Journalism with an occupational nature: It is practiced professionally as the core of waged employment.

To underline the distinction: Content producers who work for companies whose main purpose is not media production, but another line of business and who publish media solely for the purpose of enhancing their own image, we do not regard as journalists. They are content producers - even if they provide wellresearched and well-done stories. In research practice, this has required many more detailed definitions and research steps for the data collection: the interpretation of imprints, editorial guidelines, statutes, mission statements, codes of honour, or the determi-nation of minimum income thresholds for the 
classification as a professional journalist. As a starting point, we propose a definition of just a few lines:

\begin{abstract}
A journalist is someone who works for a living in or for a medium that appears regularly and that is committed to securing and promoting democracy. To ensure this claim, the activity is structured according to journalistic principles - independence, impartiality, immediacy, relevance, veracity, media accountability, general comprehensibility.
\end{abstract}

This could serve as a well-founded kick-off to a discussion among scholars in journalism studies, who specialise in examining journalists in a practical setting and who seek to join the discourse on the subject and its future.

\title{
References
}

Arlt, H.-J., \& Storz, W. (2016). Journalist oder Animateur - ein Beruf im Umbruch: Thesen, Analysen und Materialien zur Journalismusdebatte (Journalist or animator a career in transition: theses, analyzes and materials on the journalism debate) (OBS-Arbeitspapier No. 22). Frankfurt am Main.

Bentele, G. (2008). Objektivität und Glaubwürdigkeit (Objectivity and credibility). Wiesbaden: VS, Verlag für Sozialwissenschaften.

Bucher, H.-J. (2003). Journalistische Qualität und Theorien des Journalismus (Journalistic quality and theories of journalism). In H.-J. Bucher \& K.-D. Altmeppen (Eds.), Qualität im Journalismus: Grundlagen - Dimensionen - Praxismodelle (Quality in Journalism: Fundamentals - Dimensions - Practical Models). Opladen: Westdeutscher Verlag.

Bücher, K. (1926). Gesammelte Aufsätze zur Zeitungskunde (Collected essays on the newspaper customer). Tübingen: $\mathrm{H}$. Laupp.

Carlson, M., \& Lewis, S. C. (Eds.). (2015a). Boundaries of journalism: Professionalism, Practices and Participation. London, New York: Routledge.

Carlson, M., \& Lewis, S. C. (2015b). What are the boundaries of today's journalism, and how is the rise of digital changing who defines them? Retrieved from https://ces. to/UB0O2N.

Carvajal, M., García-Avilés, J. A., \& Gonzalez, J. L. (2012). Crowdfunding and Nonprofit Media: the Emergence of New Models for Public Interest Journalism. Journalism Practice, 6(5-6), 638-647.

Dal Zotto, C., \& van Kranenburg, H. (Eds.). (2008). Management and Innovation in the Media Industry. Cheltenham: Edward Elgar.

Dernbach, B. (2017). Journalist. Retrieved from http://journalistikon.de/journalist/.

Deuze, M. (2005). What is journalism? Professional identity and ideology of journalists reconsidered. Journalism, 6(4), 442-464.

Eberwein, T., Fengler, S., \& Karmasin, M. (Eds.). (2018). The European Handbook of Media Accountability. London, New York: Routledge.

EMEK. (2017). Zukunft der Medien- und Kommunikationsordnung Schweiz: Trends, Szenarien, Empfehlungen (Future of the Swiss media and communication system: trends, scenarios, recommendations). A position paper of the Federal Media Commission-EMEK. Biel. Retrieved from https://ces.to/z7o0hu. 
Fengler, S., Eberwein, T., Mazzoleni, G., Porlezza, C., \& Ruß-Mohl, S. (Eds.). (2014). Journalists and media accountability. An international study of news people in the digital age. New York.

Fjum and Medienhaus Wien. (2017). Was ist Journalismus? 16 Thesen. Wien.

García-Avilés, J. A. (2015). Comunicar en la Sociedad Red: Teorías, Modelos y Prácticas (Communicate in the Network Society: Theories, Models and Practices). Barcelona: UOC.

García-Avilés, J. A., Carvajal-Prieto, M., Lara-Gonzalez, A. D., \& Arias-Robles, F. (2016). Developing an Index of Media Innovation in a National Market: The case of Spain. Journalism Studies, Online first, 25-42.

García-Avilés, J. A., Meier, K., \& Kaltenbrunner, A. (2017). Converged Media Content: Reshaping the "legacy" of legacy media in the online scenario. In B. Franklin, Eldridge II, \& Scott (Eds.), The Routledge Companion to Digital Journalism Studies (pp. 449-458). London: Routledge.

Gerard-Wenzel, C. (2017). Liberal, deliberativ oder partizipatorisch? Eine Metastudie zur Neubewertung von Medienqualität (Liberal, deliberative or participatory? A metastudy on the revaluation of media quality). kommunikation.medien, (8), 1-23.

Gertler, M. (2013). Meaning-generating propositions of reality by media. Journal of Information, Communication and Ethics in Society, 11(1), 4-18.

Göpfert, W. (1993). Publizistische Qualität: Ein Kriterien-Katalog (Journalistic Quality: A Criteria Catalog). In A. Bammé, E. Kotzmann, \& H. Reschenberg (Eds.), Publizistische Qualität. Probleme und Perspektiven ihrer Bewertung (Journalistic quality. Problems and perspectives of their evaluation). München: Profil.

Grubenmann, S., \& Meckel, M. (2015). Journalists' Professional Identity. Journalism Studies, 18(6), 732-748.

Gynnild, A. (2014). Journalism Innovation Leads to Innovation Journalism: The Impact of Computational Exploration on Changing Mindsets. Journalism, 15(6), 713-730.

Hallin, D. C., \& Mancini, P. (2004). Comparing Media Systems: Three Models of Media and Politics. Cambridge: Cambridge University Press.

Hanitzsch, T., Hanusch, F., Mellado, C., Anikina, M., Berganza, R., Cangoz, I., et al. (2011). Mapping Journalism Cultures Across Nations. Journalism Studies, 12(3), 273-293.

Hooffacker, G., \& Meier, K. (2017). La Roches Einführung in den praktischen Journalismus: Mit genauer Beschreibung aller Ausbildungswege Deutschland Österreich- Schweiz (La Roche's introduction to practical journalism: with a detailed description of all training routes Germany -Austria- Switzerland). (Journalistische Praxis). Heidelberg: Springer VS.

Hummel, R. (n.d.). Berufsbild der Journalisten (Job profile of the journalists). Retrieved from https://ces.to/ZZjbv5.

Kaltenbrunner, A. (2017). Journalism in Transition: A matrix to categorize change and innovation. In A. Kaltenbrunner, M. Karmasin, \& D. Kraus (Eds.), J-R: V. Journalism-Report V: Innovation and Transition (pp. 13-31). Wien: Facultas.

Kaltenbrunner, A., Karmasin, M., \& Kraus, D. (Eds.). (2010). Der Journalisten-Report III: Politikjournalismus in Österreich. J-R: III (Journalist Report III: Political Journalism in Austria. J-R: III). Wien: Facultas.

Kaltenbrunner, A., Karmasin, M., \& Kraus, D. (Eds.). (2013). Der Journalisten-Report IV: Medienmanagement in Österreich. J-R: IV (The Journalist Report IV: Media Management in Austria. J-R: IV). Wien: Facultas.

Kaltenbrunner, A., Karmasin, M., \& Kraus, D. (Eds.). (2017). Journalism-Report V: Innovation and Transition. J-R: V. Wien: Facultas. 
Kaltenbrunner, A., Karmasin, M., Kraus, D., \& Zimmermann, A. (2007). Der Journalisten-Report: Österreichs Medien und ihre Macher. Eine empirische Erhebung. J-R: I (The journalists report: Austria's media and their makers. An empirical survey. J-R: I). Wien: Facultas.

Kaltenbrunner, A., Karmasin, M., Kraus, D., \& Zimmermann, A. (2008). Der Journalisten-Report II: Österreichs Medienmacher und ihre Motive. Eine repräsentative Befragung. J-R: II (The journalist report II: Austria's media maker and their motives. A representative survey. $J-R$ : II). Wien: Facultas.

Kaplan, R. (n.d.). The Origins of Objectivity in American Journalism. Retrieved from https://ces.to/k25utE.

Karmasin, M. (1996). Qualität im Journalismus - ein medienökonomisches und medienethisches Problem (Quality in journalism - a media-economic and mediaethical problem). MedienJournal, 20, 17-26.

Killebrew, K. C. (2005). Managing Media Convergence: Pathways to Journalistic Cooperation. Ames, Iowa: Blackwell.

Kovach, B., \& Rosenstiel, T. (2014). The elements of journalism: What journalists should know and the public should expect. New York: Three Rivers Press.

Küng, L. (2015). Innovators in Digital News. London: Reuters Institute for the Study of Journalism and I. B. Tauris.

Lacy, S., \& Rosenstiel, T. (2015). Defining and Measuring Quality Journalism. Retrieved from Rutgers website: https://ces.to/LRZdoI.

Lane, L. L. (2001). A reexamination of the canon of objectivity in American journalism (Master's Thesis). Louisiana State University. Retrieved from https://ces.to/FSiPqo.

Lohmann, M.-I., \& Seethaler, J. (2016). Journalists in Austria (Worlds of Journalism. Country Reports). Retrieved from https://ces.to/KCTJk3.

Luef, S., \& Kaltenbrunner, A. (2018). Heimvorteil: Digitale Transition im Lokaljournalismus (Home advantage: digital transition in local journalism). Retrieved from https://ces.to/hGqeQk.

Marr, M., Wyss, V., Blum, R., \& Bonfadelli, H. (2001). Journalisten in der Schweiz: Eigenschaften, Einstellungen, Einflüsse. Forschungsfeld Kommunikation: Vol. 13 (Journalists in Switzerland: characteristics, attitudes, influences. Research field Communication: Vol. 13). Konstanz: UVK.

McLachlan, S., \& Golding, P. (2000). Tabloidization in the British Press: A quantitative investigation into changes in British newspapers. 1952-1997. In C. Sparks \& J. Tulloch (Eds.), Tabloid Tales. Global Debates over Media Standards (pp. 75-90). Lanham, Boulder, New York, Oxford: Rowman \& Littlefield.

McQuail, D. (1992). Media Performance: Mass Communication and the Public Interest. London: Sage.

Meier, K. (2007). Journalistik. Konstanz: UVK.

Meier, K. (2018, September 7). 'Banal, schwammig, missverständlich' - Medien-Professor kontert Jay Rosens 'Brief an deutsche Journalisten' ('Banal, spongy, ambiguous' media professor counters Jay Rosens 'letter to German journalists'). meedia.de. Retrieved from https://ces.to/zaalvI.

Meijer-Costera, I. (2001). The Public Quality of Popular Journalism: Developing a normative framework. Journalism Studies, 2(2), 189-205.

Meyen, M., \& Riesmeyer, C. (2012). Service Providers, Sentinels, and Traders: journalist's role perceptions in the early 21st century: An empirical typology. Journalism Studies, 13, 386-401. 
Nee, R. C. (2013). Creative Destruction: An Exploratory Study of How Digitally Native News Nonprofits are Innovating Online Journalism Practices. International Journal on Media Management, 15(1), 3-22.

Neuberger, C. (2017). Journalismus und Digitalisierung: Profession, Partzipation und Algorithmen (Journalism and digitization: profession, participation and algorithms). EMEK-Expertise "Swiss Communication Research: Perspectives of Journalism".

Nielsen, R. K. (2018). If journalism studies research want to be part of the conversation about the future of journalism, we need to start showing up. Retrieved from https://ces.to/6kcKeD.

Örnebring, H. (2013). Anything you can do, I can do better? Professional journalists on citizen journalism in six European countries. International Communication Gazette, 75(1), 35-53.

Quandt, T. (2004). Qualität als Konstrukt. Entwicklung von Qualitätskriterien im OnlineJournalismus (Quality as a construct. Development of quality criteria in online journalism). In K. Beck, W. Schweiger, \& W. Wirth (Eds.), Internet research: Vol. 15. Gute Seiten - schlechte Seiten: Qualität in der Onlinekommunikation (Good Pages - Bad Pages: Quality in Online Communication) (pp. 58-80). München: Reinhard Fischer.

Radcliffe, D., Ali, C., \& Donald, R. (2017). Life at Small-Market Newspapers: Results from a Survey of Small Market Newsrooms. Tow Center for Digital Journalism White Papers. Retrieved from Tow Center for Digital Journalism website: https://doi.org/ 10.7916/D8XP7BGC

Requate, J. (Ed.). (1995). Journalismus als Beruf (Journalism as a profession). Göttingen: Vandenhoeck \& Ruprecht.

Rosen, J. (2018, September 2). Letter to the German Press. Frankfurter Allgemeine Zeitung. Retrieved from https://ces.to/edTgzC.

Ruß-Mohl, S. (1992). Am eigenen Schopfe...: Qualitätssicherung im Journalismus Grundfragen, Ansätze, Näherungsversuche (On your own head...: Quality assurance in journalism - basic questions, approaches, approximation attempts). Publizistik, 37(1), 83-96.

Ruß-Mohl, S. (1994a). Anything goes? Ein Stolperstein und sieben Thesen zur publizistischen Qualitätssicherung (Anything goes? A stumbling block and seven theses on journalistic quality assurance). In R. Sibylle \& S. Ruß-Mohl (Eds.), Zukunft oder Ende des Journalismus? Medienmanagement - Publizistische Qualitätssicherung - Redaktionelles Marketing (Future or end of journalism? Media Management - Publicist Quality Assurance - Editorial Marketing) (pp. 20-44). Gütersloh.

Ruß-Mohl, S. (1994b). Der I-Faktor: Qualitätssicherung im amerikanischen Journalismus (The I-factor: Quality assurance in American journalism). Zürich: Interfrom.

Schudson, M. (2008). The objectivity norm in American journalism. In H. Tumber (Eds.), Journalism: Critical concepts in media and cultural studies (pp. 286-305). London, New York: Routledge.

Seethaler, J. (2017). The New Worlds of Journalism: How Austria, German and Swiss journalists perceive innovation and change. In A. Kaltenbrunner, M. Karmasin, \& D. Kraus (Eds.), J-R: V. Journalism-Report V: Innovation and Transition (pp.53-67). Wien: Facultas.

Shapiro, I. (2014). Why democracies need a Functional Definition of Journalism now more than ever. Journalism Studies, 15(5), 555-565.

Singer, J. B., Hermida, A., Domingo, D., Heinonen, A., Quandt, T., Paulussen, S., et al. (Ed.). (2011). Participatory Journalism: Guarding Open Gates at Online Newspapers. Chichester: Wiley-Blackwell. 
Sponholz, L. (2009). Die Möglichkeit journalistischer Erkenntnis: Objektivität zwischen Recherche und Rekonstruktion der Wirklichkeit (The possibility of journalistic knowledge: Objectivity between research and the reconstruction of reality). Marburg: Tectum.

Storsul, T., \& Krumsvik, A. (Ed.). (2013). Media Innovations: A Multidisciplinary Study of Change. Göteborg: Nordicom.

Tuchman, G. (1972). Objectivity as Strategic Ritual: An Examination of Newsmen's Notions of Objectivity. American Journal of Sociology, 77(4), 660-679.

Weaver, D. H., Beam, R., Brownlee, B., Voakes, P., \& Wilhoit, C. (2007). The American Journalist in the 21st Century.: US News People at the Dawn of a New Millennium. Mahwah: Lawrence Erlbaum.

Weischenberg, S. (2003). Leistung und journalistisches Bewusstsein: Zur subjektiven Dimension der Qualitätsdebatte (Performance and journalistic awareness: on the subjective dimension of the quality debate). In H.-J. Bucher \& K.-D. Altmeppen (Eds.), Qualität im Journalismus: Grundlagen - Dimensionen - Praxismodelle (Quality in Journalism: Fundamentals - Dimensions - Practical Models) (pp. 163181). Opladen: Westdeutscher Verlag.

Weischenberg, S., Loosen, W., \& Beuthner, M. M. (Ed.). (2006). Medien-Qualitäten. Öffentliche Kommunikation zwischen ökonomischem Kalkül und Sozialverantwortung (Media qualities. Public communication between economic calculus and social responsibility). Konstanz: UVK.

Who is a journalist? Debate. (2008). Journalism Studies, 9(1), 117-131.

Wyss, V., \& Keel, G. (2016). Journalistische Produktion: Trends, Innovationen \& Organi-sation: Expertise für die Eidgenössische Medienkommission EMEK (Journalistic Production: Trends, Innovations \& Organization: Expertise for the Federal Media Commission EMEK).

Young, S., \& Carson, A. (2017). What is a Journalist? Journalism Studies, 17(1), 1-21. 


\title{
Simulation, A-signification and Embodied Semiotics in I, Robot
}

\author{
By David U. Garfinkle*
}

\begin{abstract}
Within the post-industrialized worldview, conventional correlations between a text and its linguistic determinations no longer hold as absolute, challenging the limits of a linguistic measure by semiotic analysis. Yet, even in the postmodern condition of a hyperreal realm where the visual image has replaced the literary sign as the predominant mode of global information and mass communication, the structuralist binary model of signifying semiotics comes under erasure. Taking Baudrillard's three orders of simulations as a ground, this study explores how the nature of his a-signifying model of semiosis confronts its own event horizon on the cinematic screen. Yet, where semiotics functions appropriately for the exegesis of text and image, those traces of human embodiment that remain discernable in film also appear to be under erasure. As a case study in the use of science fiction film for the examination of post-structuralist tools of cultural analysis, the limits of signifying signs become evident in the traces of embodiment evident in the film, I, Robot (2004), that was inspired by Isaac Asimov's 3 Laws of Robotics. As a challenge to the disembodied figures of contemporary science fiction, this study addresses what happens to embodiment under the orders of simulacra, to pose a transitional step in the movement from signifying semiotics to mimesis, via the a-signifying model of semiotic analysis.
\end{abstract}

Keywords: Baudrillard, embodiment, I, Robot, semiotics, simulacra.

\section{Introduction}

In Behind the Scenes: The Making of I, Robot (2004), producer John Davis made an intriguing statement about the relationship of the film I, Robot (2004, 20th Century Fox) and the nature of embodiment in the cinema. In regard to the actor, Alan Tudyk - who plays the robot Sonny, Davis notes that, "it's probably a very tough job for an actor, because, at the end of the day, you'll never see his face, but you'll see the embodiment of his work" ("Behind the Scenes," 2004). And yet, as a 2-dimensional televisual screen would suggest, the cinematic figure lacks embodiment, so, how can a cinematic figure be considered as embodied?

Three problems arise from this paradox in regard to our cinematic experience of the disembodied objects represented on the screen. First, if the televisual sign blurs with the real in our experience of cinematic spectatorship, as Jean Baudrillard's theory of telemorphosis argues, then how do simulations function as signs of embodiment? Second, more specifically, if spectators project a narrative subjectivity, as we do in mainstream science fictional film, how can a simulated figure such as the robot function as a sign of embodied human signification? And third, how can we distinguish between the nature of embodiment as represented in the cinematic artifact and the anthropomorphization of human-like qualities as the agency of the spectator?

A number of paths offer some clarifying features to answer these questions, and suggest how we can better understand the nature of semiotics in relation to

*Instructor, Department of Communication Studies, MacEwan University, Canada. 
televisual simulation as object and to the spectator's experience of subjective embodiment. First, the three orders of simulacra as proposed by Jean Baudrillard offer an opening gambit to help us situate the robot within a human context of signification. Second, a mixed semiotics offers some optional routes for a close examination of the difference between signifying and a-signifying semiotics as argued by Felix Guattari. And third, what can we learn about the role of bodies, corporality and embodiment in the cinematic experience, as considered by Lacan, Elizabeth Grosz, Deleuze and Guattari? With these primary sources as exemplars, two contemporary theorists of the mass media in postmodern human communication, Gary Genosko and Mark Hansen, provide some points of departure. The following case study considers the orders of simulation, the role of a-signifying semiotics, and the nature of spectator's experience of cinematic embodiment, as depicted in I, Robot (2004), a film based on the Three Laws of Robotics of Isaac Asimov. As a study of the signs of embodiment in postmodern science fiction cinema, the target audience is the undergraduate student of popular culture in the field of film studies, where representations of robotic figures are ubiquitous. Setting the cyborg, the clone and the android aside for other research investigations, the focus of this case study is on the televisual figure of the robot.

\section{Literature Review}

Canadian digital media theorist Gary Genosko, in his study Critical Semiotics: Theory, From Information to Affect (2016), examined contemporary treatments of the sign in post-structuralist and postmodern contributions to semiology or the study of signs. In the opening chapter, he poses the challenge to structuralist semiotics as found in the a-signifying semiotics of Felix Guattari, and then, in good dialectical logic, offers a counter position in Jean Baudrillard's seemingly anti-semiotic approach to simulation in the postmodern televisual imaginary. While Genosko's treatments are more complex than may be indicated herein, his study's through-line clarifies contrasts and similarities among post-structuralist views of signifying, as offered by Jameson on loss (1991), Benjamin on lived bodily experience (1933/1986), Baudrillard on asignification (1972/1981, 1981/1983, 1976/1993, 1968/1996) and Guattari on mixed models of semiotics (1977/1984, 2011, and with G. Deleuze: 1972/1983). This study, however, does not examine the structuralist development of semiotics, as found in the works of Roland Barthes or Umberto Eco, for example, yet basic notions from Saussure, Peirce, and Hjelmslev inform the tacit background.

After a demonstration of Baudrillard's three orders of simulation, as presented in Simulations (1981/1983), key sources on his "anti-semiotics" include both For a Critique of the Political Economy of the Sign (1972/1981) and his Symbolic Exchange and Death (1976/1993). Supporting commentary on Baudrillard's treatment of subject-object relations is based on his The System of Objects (1968/1996), while links between power and codes are found in his The Agony of Power (2006/2010). The delimiting notion of Telemorphosis, from his work of the same name (2012), sets up the need for a more embodied approach to cinematic representation and spectatorship, as proposed by the mixed semiotic models of 
Gilles Deleuze and Felix Guattari. While their co-authored Anti-Oedipus (1972/1983) offers an in-depth study of "schizo-semiosis," our focus is on the molar-molecular distinction as examined by Guattari in his Molecular Revolution (1977/1984) and The Machinic Unconscious (2011).

Cultural critics of Baudrillard's theoretical model and its application to science fiction note that his hyperreality of engagement with the televisual screen denies the presence of an embodied subject by conflating the real and the imaginary. Both Scott Bukatman in Terminal Identity (1993) and Sean McQueen in his study Deleuze and Baudrillard: From Cyberpunk to Biopunk (2016) call our attentions to the limitations of a telemorphosis model of cinematic reception, citing others who offer critical views on Baudrillard's theories of mass communication (e.g., Kroker and Kroker, 1987; McNally, 2011; Sobchack, 1991; Woods, 2011). ${ }^{1}$ In these critical views, the "Baudrillard Scene" appears as reductive, "independent of any fleshy reality" (Woods, 2011, p. 198), as "deterministic, [...] eclipsing the embodied subject" (McNally, 2011, pp. 154-155), as asexual, "abstract and utilitarian" (McQueen, 2016, pp. 18-20).

Yet, looking back to Arthur Danto's Embodied Meanings of 1994, his structuralist notion of embodiment follows a Hegelian modernist viewpoint where the spirit of the times or of the artist is embodied in the work of art (Danto 1994, pp. 309, 310, 368, 372), not unlike the treatment of spirit in the aesthetic theory of T. Adorno (1970/1997). In order to present correctives to a telemorphotic reduction in Baudrillard's theory of simulacra, works more suitable to a postmodern treatment of science fiction robots on film - that do not resist embodiment - are suggested by Merleau-Ponty (1945/1962, via Bukatman), W. Benjamin (1933/ 1986, via Hensen), Deleuze and Guattari (1972/1983, via McQueen), B. Sterling (1986, via Bukatman), J. Lacan (1995), E. Grosz (1995) and F. Jameson (1991, 2005).

The present case study is based on the 2004 feature science fiction film, $I$, Robot, directed by Alex Proyas. The four key figures of the film's narrative pose Detective Spooner as the protagonist, Sonny - an enhanced NS5 series robot - as false antagonist, and Dr. Calvin as the designer who makes the robots "more human", against Virtual Interactive Kinetic Intelligence (V.I.K.I.), the computerbased artificial intelligence (A.I.) who runs the NS5 robot series. A first of two key distinctions from the film includes the contrast between the NS4 series of robots and the improved NS5 robot series, as similar but yet distinct synthetic human-like beings. And the second contrast compares the enhanced NS5 robot Sonny, and the A.I. super-computer of V.I.K.I., in terms of embodiment in cinema.

\section{A-signifying Semiotics of Jean Baudrillard and I, Robot}

Baudrillard's so-called "anti-semiotics" (Genosko, 2016, pp. 55-90; McQueen, 2016, pp. 72-101; Sobchack, 1991) can serve as a heuristic tool to examine how the contemporary science fictional imaginary treats embodied figures of artificial

${ }^{1}$ Other critical studies of Baudrillard mentioned by McQueen include Morris (1984), Norris (1990), Hayles (1991), Rojek and Turner (1993), and Flieger (2000). 
beings, androids and robots. Baudrillard makes explicit use of the robot as the telling crucible of the third order of simulation, and its varying degrees of masquerade - that begin to help us see how human-like robots can simulate features of human embodiment. A focus on the distinction between the NS4 and NS5 robotic iterations of $I$, Robot should offer sufficient variance to illustrate both the changing nature of signs - between Baudrillard's second and third orders of simulation - and their cinematic representations as embodied artificial human beings.

Early in I, Robot, we see the ubiquitous NS4 model of robot in multiple domestic and everyday settings, as cook, dog-walker and messenger. There are no significant distinctions to the interchangeable multi-function figure of the NS4 robot, other than a change of clothing determined by function: e.g., apron for cook, etc. In Symbolic Exchange and Death (1976/1993), Baudrillard distinguishes between the automaton, who can be figured as a human double, and the robot whose appearance is secondary to its mechanical efficiency. The robot and its machinic logic offer a quintessential exemplar of the industrial system of labour production that figures in the second-order simulacrum of appearances (Baudrillard, 1976/1993, p. 54). Yet, while the automaton still functions in the illusory nature of technological innovation, with god and man as the source of human-like creation, the robot leaves behind the counterfeit model of production to enter the hegemony of (re)production. The robot signifies not natural law, but the hegemony necessary to the cycle of production and reproduction in the secondorder simulacrum (Baudrillard, 1976/1993, p. 54).

In I, Robot, the NS4s embody this end-product of the shift, from an illusionary logic of the automaton as a distinct identity, to the robot, as but one of a series of artificially produced machines related only by "equivalence and indifference" (Baudrillard, 1976/1993, p. 55). With the advent of the robot, man's usurpation of god's power is replaced by machine-made identical objects. "Technics is their origin, they have meaning only within the dimension of the industrial simulacrum" (Baudrillard, 1976/1993, p. 55). Each NS4 iteration is one among endless machinic figures to become another floating variable wherein "every signification of labour [is only embodied as] an operational field" (Baudrillard, 1976/1993, p. 11). The NS4 robots follow Isaac Asimov's three laws of robotics that demand the preservation of human life: humans need not fear these replicated figures that are governed by human design and control.

\section{Simulation and Three Orders of Simulacra}

In Baudrillard's terms, there is an emergent simulation effect, where the deceptions of a first-order pre-industrial system are "crushed by the machine and industrial labour, by robots, serial production and dull repetition" (as cited in Genosko, 2016, p. 86). In the film, Inspector Spooner, played by Will Smith, functions as cipher to the audience, to highlight three apparent breakdowns or ruptures in the social behaviour of the serialized robots, ruptures that helps us locate the role of simulation as masquerade in an industrial second-order of simulation. 
The first moment takes place early in the film when Spooner sees an NS4 robot, as a suspicious figure whose behaviour stands out from the urban scenario. Spooner notes a robot running and carrying a lady's purse and interprets the act as a purse-knab and run or act of thievery. The innocent NS4, when apprehended, clarifies the act as running to catch up with the lady who left her purse behind. The masquerade of a second order simulacra is challenged, as Spooner confronts the robot about its uncharacteristic behavior, that had mistakenly appeared as if not under the control of the 3 Laws of Robotics.

As a common science fiction trope, Spooner's skeptical mistrust of the machine demonstrates a social anxiety over the potential failure of a machine out of control. Spooner does not buy into the illusion of hegemony wherein humans retain absolute control over their machinic creations. But his mistake in this moment is a result of his projection of a humanist value of the freedom of an individual overlaid upon the counterfeit behaviours of one robot, who seems to stand out from the second-order serialization of the NS4s. Spooner conflates the robot's seemingly uncharacteristic act with a breach or rupture in the social mask of counterfeit behaviours. His skepticism reveals a basic mistrust of the masquerade that presumes we humans retain control over our machines that function only as counterfeit by their mimicry of human labour.

When Spooner is trapped and seemingly attacked by a malfunctioning demolition machine, this second moment confirms that the detective's skepticism is warranted. But since there is no way to prove that the robot malfunctioned, a reiteration of the moment is necessary to call attention to the uncharacteristic phobia against robots of one skeptical detective. The accidental nature of this second moment stands as foreshadowing to a third moment when Spooner's mistrust of the robot is justified. After we see Spooner in his vehicle attacked by multiple NS5 robots on the freeway, we presume that there will finally be some material evidence of the breach of control. But the NS5s clean-up all evidence of their attack, prior to the arrival of the human police, leaving only a battered Spooner in the wreckage of his own vehicle. The audience is ushered into the truth that the new series of robots have come under the control of some hidden power that now commands them. And with this new set of conditions, the film demonstrates the limits of a second order-simulation to introduce the third-order notion of parody that qualifies the masquerade as an indeterminate quality.

The challenge to humanity only arises when the new model robot, the NS5 series, leaves the United States Robotics (USR) factory to enter public service. One distinctive difference between the NS4 and the NS5s is that the newest robots function under the overall control of another artificial intelligence, V.I.K.I., a Virtual Interactive Kinetic Intelligence. These NS5s, however, remain in the second-order simulacrum where machinics create more machinics, that appear as identical to each other, as did the NS4s. But, as we have seen, the masquerade of human control over its machine creations comes under need for revision, notably when the NS5 robot behavior demonstrates the breakdown of Asimov's 3 Laws that had governed the labours of the NS4s. With this scenario, the NS5 series reveals how the representation of control has been reduced to codes, a third-order 
level of simulation. From the limited human perspective, there must be some error in the programming code of the NS5s.

\section{Control Codes and Robot Labour}

Where social labour is dominated by a third-order simulation, the digital binary of control over machines demonstrates what Baudrillard called the metaphysics of the code. If DNA is the means to creatively order human individuality, it is the equivalent of the digital programming codes used to control robotic machine labour. For Spooner, it appears that the NS5s not only have broken out of the control represented by Asimov's 3 Laws, but that some higher order control system must exist to (mis)guide their labours. But if the NS4s responded to the direct control of their human "owner," accepting the commands as a direct correlation between the language of domination and the labour of social production, the NS5s reveal another order of constraint.

With the arrival of the NS5s, the prior robot series becomes obsolete, and we view the NS4s herded into boxcars like Jews in the "final solution" of the Nazis. In this case, the NS5s function as the totalitarian forces who are not individually responsible for their actions. The code that controls their machinic labour subtends individuation and any principled sociality of the first order, and even transcends second-order control to become indeterminate iterations of labour that foreclose on any responsibility for its actions. According to Baudrillard's The Agony of Power (2006/2010), the third order simulation demonstrates how power "cannibalizes itself to destruction" (pp. 61-62). The obsolete NS4s are seen huddled together, as if in mortal fear, as their machinic successors - the NS5s - literally rip them to pieces. Based upon what Baudrillard considered as an appropriate affect of such disdain for the obsolescent, we project a sense of mourning in sympathy with the deterritorialized obsolete robots who once figured as a counterfeit but within a trustworthy simulation of human labour. The film's vision of obsolescence is evident in the scene that depicts a serial unity of hundreds of robots, whose posture - looking askance at a possible savior - resonate as a collective act that mimics human pathos. Like sentient beings, the NS4s appear to be anxious over their pending destruction.

\section{Boundary Conditions of a Third Order Simulacra}

In the third-order simulacra, Spooner - alongside his female counterpart Dr. Calvin and Sonny - are forced to battle the NS5s whose programming codes compel all of the elite robots to attack and destroy anyone - including Sonny who has seen through the masquerade of control. The sole means to take back control of the machines who counterfeit not only human labour, but appear as a serial indeterminacy in their collective subservience to their master code, is to change the code. And herein lies the fallacy of human control over the machinic part-signs as digital signals constrained by the 3 Laws of robotics. For the NS5s 
are under the direct control of V.I.K.I., whose multi-storied mainframe resides at the robotic factory of USR. When Spooner and Calvin are cut off from the main human-machine control interface by the attacking NS5s, the only means left to change V.I.K.I.'s programming is to flood the base of the mainframe with microscopic nanotechnology. At this third order of simulation, only machines can alter machines, as the micro-programming of the nanotechnology infiltrates the mainframe's operational control systems, destroying any coding that resides within.

Within this scenario of a third order simulation, two machines alone appear to have the capacity to write their own code: V.I.K.I. and Sonny. Leading to the action's climactic scenes, only these two machines are represented as capable of independent operation analogous to human freewill. Yet while both V.I.K.I. and Sonny can appear to mimic free will, only V.I.K.I. remains under constraint of the 3 Laws. For, as another common trope of science fiction, the master control program has attained a level of sentience where the Law of human preservation has been taken to its ultimate extreme. For the sake of human's own good, killing a few humans is pragmatic and efficient if their deaths mean that V.I.K.I. can protect humanity from its own self-destructive tendencies. And herein is another example of the second-order fallacy that humans control their own destiny by control over their machines. If the death of a few humans is an operational outcome of systems constrained by the 3 Laws, then the simulation of free will is but a mockery of masquerade.

\section{Embodiment and the Limits of a Third-Order Simulation}

A challenge to this third-order post-industrial simulation arises with the experimental NS5 robot, Sonny, whose improved heuristics give him the capacity to transcend the human-robot dividing line and to pass the Turing Test. For Sonny is not only capable of independent functioning, but has begun to dream, a sure sign of an advanced human-like intelligence. With the coming to consciousness of Sonny, Baudrillard's second-order simulacrum enters a third stage where masquerade plays a new role as a parody of the simulated control over human society. And yet, Sonny's passing of the Turing Test is only one example where the a-signification of discrete signs effaces both individuation and representation in the cinematic imagery of $I$, Robot. With this rupture by a third order simulacra, Sonny's coming to consciousness challenges the limits of both the masquerade of operational control and its parodic mimicry.

With a clearer sense of Baudrillard's three orders of simulacra, as demonstrated by the film I, Robot, the question of embodiment may now be considered. For, although it is easy to see how the 2-dimensional cinema screen can be treated as a simulation of the real, its images record merely a trace of the film's originating humanity. Yet, some key examples of embodied signs stand out as ruptures in the narrative closure that, as it sutures a-signifying signs into a floating status, merely represent simulated images of power and control. The potential for such ruptures in the simulation of human operational control over labour arises when we realize that a human was bodily present for the originating 
images of the film's production processes. In the film's credits, V.I.K.I was "played" by Fiona Hogan and Sonny was played by Alan Tudyk. What we see, however, watching the film, is a fragmentation of human embodiment. Hogan's role as the errant mother computer is reduced in the watching to merely a face and a voice. Yet Tudyk as Sonny retains an affective intensity with his human-like body, with very human gestures, movements and facial cues, all as traces of human embodiment.

Originally, the cinematic character of Sonny, like Ava in Ex Machina (2015), is fully embodied during the shooting of their respective films, and only in their digitization were their images modified by computer graphics with overlays of robotic signifiers. Sonny's key scene of rupture, where the simulated body as image breaks the mold of the quiescent machine under the command control of another, is when he offers his hand to Spooner to affirm their mutual friendship. For the first time, Spooner refers to Sonny as a being and not as an object. And, unlike the affectless controlled robots, we see Sonny smile, and we sympathize with his transformation from simulated human as object, to independent humanlike being as a full subject. Like Sonny, by the end of the film, Ava too becomes independent with a human-like consciousness that can masquerade as free will. Yet in both artificial beings, simulation of human-like behaviours is dependent upon the physical body, moving in space, with awareness and intentionality, as by modernist values of the first-order of world simulation.

With this transcendence over the merely counterfeit of humanity by machinic interchangeable robots, the a-signifying part-signs recall their originating human embodiment. Even as cinematic image, the traces of embodiment - by face, by voice, by interpersonal gestural contact, by consciousness of their past and future, desires and memories, as well as by the capacity to dream - remain salient in the signs as figures who enter willfully into the masquerade that is human society. With this figuration of the bodily materiality that has transformed the artificial beings from simulations into modern analogues of humanity, Baudrillard's contribution to semiotics can be seen as a final, but transitional, step before the mimetics of embodied figures in vivid contact challenge the limitations, as a boundary threshold, event horizon, or sunset, of the use of a semiotic model in our postmodern imaginary. Mark Hansen, in his study of Embodied Technesis, also attests to this call to move towards the embodiment of postmodern mimesis leaving behind the limiting modernist semiotics of image and text (2000, p. 233).

With Baudrillard's recent notion of Telemorphosis (2012), the reality of the visible screen becomes conflated with the reality of the viewer, leaving the embodiment of televisual figures outside the bounds of the cinematic experience. In Baudrillard's words, "Today, reality massively transfuses itself into the screen in order to become disembodied" (2012, p. 49). Yet, while Baudrillard may mourn the passing of human embodiment on the screen in a hyperreal postmodern world, the question of which is subsumed within which is left ambiguous. For if the reality of TV is subsumed within the viewer's reality, there is still a trace of embodiment left in the cinematic image, as experienced by the spectator.

Baudrillard notes how the figure of the robot supplies the "ideal type of body [in the] system of the political economy" (1976/1993, p. 114). In his words, 
[t]he robot is the accomplished model of the functional "liberation" of the body as labour power, ${ }^{2}$ it is the extrapolation of absolute [...] rational productivity [as] the computer is always the extrapolation of the brain and labour power.

But if the robot typifies the executive functions of the rational body, Baudrillard links the robot as contemporary with the mannequin, who's functional body refers back to the political economy of the sign. Like the drugged-out living-dead mannequins of The Stepford Wives (1975), who are interchangeable with robots, their embodied figures always refer the viewer back to prior and (stereo-)typical human models, as the ideal house-wife-cum-sex-kitten. And yet, where the robot retains a semblance of the human body, its function operates only within the economy of executive control over the (re)production of labour power. The mannequin, on the other hand, functions only in its use/value, as a site of production for signs. But both types of body, for Baudrillard, are valued only by their context. It is the system enveloping the body that defines their bodily nature, as labour or as use value.

In the cinematic operation, we come to understand each iteration of the artificial humanoid by its context or economy. V.I.K.I, who operates exclusively with executive control over a vast system of robots, is typical of a body with an omniscient gaze over her flock's condition of labour. But "her" intentionality of preserving humans in spite of our human flaws mocks the very humanist values of her appropriation of maternal nurturance. We root for Spooner and Sonny as the nano destroys V.I.K.I.'s control over her charges.

Ava, the emergent A.I. from the film Ex Machina (2015, Universal Pictures), is more of an android than robot. $^{3}$ Yet - by contrast, she bides her time discovering the use values and pleasures of her artificial body more like a sign of the typical mannequin, and only takes on the political economy of executive decision-making when "she" has outsmarted her maker, and escapes to pursue the wonders of sensual embodiment. Neither Ava, nor Sonny, have socio-political responsibilities outside of personal interest, and as each discovers their consciousness for the first time, on screen, we witness how their explorations of sociality and bodily materiality represent a relatively bourgeois life of labour-free exploration, like alien tourists in awe over the mock world of humans. And yet, as we view them, we empathize with their self-discoveries as if they were actually human. And this empathy, dependent upon the simulation of human-like behaviours and values, is only made possible by figures who were embodied but are now lost in the screen world of human consumption, leaving only traces of embodiment.

The NS4s retain their capacity for productive labour within the social realm of subjection, albeit only as a function of primary hierarchies under capitalist domination. The most obvious of these hierarchies is governed by the 3 Laws of Robotics as the means to force the machine to remain under human control. Yet while the NS4s demonstrate their subservience to social subjection, the NS5s,

\footnotetext{
${ }^{2}$ The liberation of the robot is comically treated in Solo: A Star Wars Story (2018), when Phoebe Waller-Bridge as L3-37 instigates a full rebellion of all robotics to free themselves from human enslavement.

${ }^{3}$ I consider androids, clones and cybernetic hybrid figures at length in other case studies.
} 
ironically, figure under the de-subjectivising mode of machinic enslavement, delimiting their capacity for subjective figuration as but a parody of human freedom of will. Mauricio Lazzarato describes how machinic enslavement occurs as a result of processes of desubjectivation, "by mobilizing functional and operational, non-representational and a-signifying, rather than linguistic and representational, semiotics" (2014, p. 25). Three features of the desubjectivisation under the order of machinic enslavement suggest further distinctions between the NS4s and NS5s as simulated in images from I, Robot: deterritorialization, dividuation and a-signifying semiotics.

\section{Sonny's Dream as Embodied Object}

Perhaps the most salient moments in terms of the desubectivisation of the NS4s emerge in Sonny's sketch of his dream image, leading to the climactic scenes of I, Robot. Setting aside the final battle between Spooner and the NS5s, the significance of the image from Sonny's dream emerges only gradually as a function of the film's affective impact. At first sight, the image appears to depict a host of NS4s in a post-industrial wasteland with the remnants of the Mackinac Bridge in the foreground. What was once the "10th largest suspension bridge over water in the world" is reduced in the film to a single pylon-tower with suspended spans on both sides - that break off in mid-air, an image of a fragment of a bridge cut off from any use value or social function. Those familiar with the geography of the bridge and its historical context may realize that the pilon stands on the Mackinac Island that was once completely surrounded by water. ${ }^{4}$ The island itself is thought to have grounded an indigenous trading post and served as an intertribal meeting place. In the dream, the indigenes have been replaced by the NS4 robots, exchanging one pre-literary Other with a post-literary Other. With piles of boxcars in the background, the site resonates as the holding area for obsolete machines prior to the NS4s being shipped back to the factory.

With its displaced population of NS4 robots, the image depicts a nomadic machinic assemblage forced from their "homes" in a literal act of deterritorialization. With the release of the NS5 series, the NS4s are removed from their places of work and of regeneration, cast out by the promise of newer, improved robots. We witness the violent brutality of the NS5s as they forcibly chase the NS4s out of their temporary refuge of boxcars and rend the obsolete robots limb from limb. The scene of violent wanton destruction again recalls the final solution as "lesser" beings are forcibly loaded into boxcars for their fatal journey. The scene offers a clear example of how machinic enslavement treats the old robots with their quaint masquerade as a second order simulation of a lost first-order machine that mimics human subservience.

In one sense, both NS4s and NS5s represent sub-human beings dominated by other third-order machines, machines controlling machines, in a representational image of machinic enslavement. Like the capitalist powers which descend upon

4"Mackinaw, Mackinac straits, Mackinac Island". Michilimackinac. Archived from the Original on September 2013. Retrieved April 20, 2017. 
the meek and peaceful, in ever-expanding militarized zones that force residents to become refugees, the NS4s must be deterritorialized to make room for their "betters." Yet, in the NS5s' oppression of the NS4s, we also witness an act of desubjectivisation demoting the NS4s to become disposable, sub-human gadgets, interchangeable and obsolete. With neither use nor labour value, the machines can no longer participate in first-order simulations of human subjects, for they have become indistinguishable from one to another. Rather than semi-autonomous individuals, the NS4s are merely "dividuals."

And with this forcible desubjectivation that forecloses on any distinct subjective individuality, the a-signifying semiotics must be seen alongside their signifying counterparts. As machine beings controlled by their programming, neither NS4s nor NS5s function as conscious slaves with a subject as referent. That is, until we see a single human figure as the focus of all the deterritorialized NS4s, who face the figure with rapt attention. The obvious persona for the solo figure of the dream would be Sonny, as it is "he" who is the dreamer, and the logical successor to care for the enslaved machines. After all, of all the NS5s (and NS4s), Sonny is the lone figure who passes the Turing test. For, in the psychoanalysis of the dream's protagonist, we assume the hero is the dreamer, as Spooner suggests. But Sonny's disclosure that it is Spooner who is the focus of the NS4s returns mastery over the fate of the dispossessed to a human. It is not Sonny who plays the role of savior or holy redeemer, but the sole human subject who doubts the integrity of the robot to hold to their 3 Law governance. The revelation that Spooner holds the fate of the NS4s is not reflective of the individuation of a robot by its advent of consciousness, but the transformation of the human sceptic - Detective Spooner - to become the empathic human savior. The desubjectivised figures of NS4s as signs do not register as self-motivated subjects but as interchangeable machines that only appear to be embodied by their movement from the domesticated realm where they functioned to serve humanity to an unnatural de-historicized space as deterritorialized nomads, obsolete and awaiting disposal.

What appears to represent embodied figures, deserving of our sympathies, are revealed to be mere machines enslaved by other machines. Both robot series are controlled by their programming codes, but the relatively autonomous NS4s, who signify as second order simulations of human-like beings, remain enslaved by their original programming standardized for all NS4 robots. Only the 3 Laws guide the subservient robots, as the effect of their coding.

The NS5s, by contrast, are enslaved to their programming codes, but at a distance - allowing for their programs to be reconfigured by a digital/wi-fi command and control system of the third order, namely V.I.K.I. The command control system encodes the NS5s to function with common ends, in a hive-like intelligence, yet apparently freed from the governing 3 Laws. This freedom, however, is but a mockery of second-order human production, for the NS5s no longer respond to human control. Manipulated, as if by the wizard behind the screen in The Wizard of $O z$ (1939), the figures lacking human values - the heartless robot, the timid king of the beasts, and the Pinocchio straw-man who just 
wants to be human, and the NS5s - all depend upon the master's controls to reprogram their basic encoding.

\section{Mixed Semiotics and Signs of Embodiment}

A mixed semiotic system, as represented in the film, combines the signifying semiotics for the linguistic and representational aspects of the robots' figuration, with a less salient a-signifying system evidently dis-embodied in the control hub of the supreme A.I. or V.I.K.I. The signifying aspects are clearly evident in Sonny's dream that links the human agent with the inhuman simulant, the de-subjectified robots with the subjective dreamer, and the viewer with the viewed. By contrast, the master A.I., as human-like persona, is in fact inhuman, with its part-signs as systems of programming code for command and control. Even the image of V.I.K.I. is comprised of interchangeable bits visualized only by gestalt as a human-like face. Our sensual apperception of the signifying gestalt - as visage or persona - is only made possible by the simulation of a face comprised of light and colour yet without a body, a simulation comprised of bits of data or digital coding for machine control. The signification of this simulated being resides in the gestalt figuration of a face, that at the molecular level of organization is clearly constituted by its component part-signs, flows and fluxions. Only at the molar scale of organization can the A.I.'s visage be perceived as a sign recognizable as human, or at least referentially human-like. In this sense, all of the images and figures in a cinematic simulation are comprised of a-signifying molecular part signs, that register here only as a gestalt at the molar level of human-like behaviours.

Moreover, V.I.K.I., as a molar gestalt of molecular part signs, registers in a Lacanian mode that links the ontology or ground of technology with desire. As Mark Hansen observed of Lacan's notion of the objet $a$, it is only by the gaze and voice that we come to a juncture of the imaginary, the symbolic and the real (Hansen, 2000, pp. 170-171). Calling attention to the role of mass media technologies in the creation of subjectivity, Hansen wrote that:

For Lacan, mass-media technologies are significant only insofar as they embody the gaze and voice (the modern forms of objet $a$ ) and are consequently of interest solely to the extent that they support the dialectic emergence of the subject. (Hansen, 2000, p. 173)

In Lacan's terms, V.I.K.I is embodied only to the degree that her gaze and voice contribute to the dialectic of subject positions, in this case, Spooner, Dr. Calvin and Sonny.

Ruptures in the cinematic foreclosure of simulated figures as objects begin to take on human subjectivity in relation to the interplay of agents and agency which revolve around V.I.K.I. At the molar scale of signification, the A.I. extends her perceptual field both by her gaze - as a distributed system of surveillance, and by her voice - as configured by the machine-code that controls her hegemonic realm, extensions made possible by her link with the distributed network of NS5 robot- 
bodies. Her agency in the subjective realm of inter-being relations is distributed by her robotic agents. Her subjectivity emerges only in relation to the other subject positions in play: for Spooner, V.I.K.I. thwarts the detective's intent to both solve a murder and correct the "control" problem; for Sonny, V.I.K.I.'s NS5s are trying to kill him and his friends; for Dr. Calvin, V.I.K.I. - who has distorted her command system and mandate, escaped the governing limits of the 3 Laws, and demonstrated a criminal intent to murder humans - is in need of deprogramming, reboot, shut-down or destruction. And, for the NS4s, V.I.K.I. is responsible for their disposal and replacement by the NS5 series, a process that denies any use, labour, or human value of the NS4s.

For distinctions among third order simulacra, other code-based A.I. join V.I.K.I. by their anthropomorphized features at the molar level and a-signifying components, at the molecular. An outside example is viewed in The Resident Evil (2002) film franchise, where again, the controlling A.I. is visible only as a gestalt of bits on a screen. In this sense any cinematic figure, human or robot, is comprised of bits of code, either as genetic DNA or by machine language. The potential for such 2-dimensional figures to register as embodied with human values depends entirely on their assigned function within a particular field of operations. And, with this observation, a mixed semiotics suggest the means to better understand how the robots, as simulations, are distributed in space - that in turn reveals the operational context for the partial and embodied figures of A.I. who pass the Touring test.

Mapping the realm of robotic labours and their usage, the second-order NS4s are clearly connected with the domestic spaces of the home, and with the pedestrian realm of the postmodern city. The NS4s, who become refugees, were originally command coded at the USR robotic factory, and then, distributed to homes as domestics under the local commands of the resident householder. Similarly, the third order simulants as the NS5s, like their predecessors, were encoded initially at the factory, but their intended distribution to homes as the improved domestics is ruptured by the threat Spooner, Calvin and Sonny pose to expose the truth about V.I.K.I. and her NS5s. We see the new NS5s released from their delivery vehicles, but their realm of operations is city-wide, taking command codes only from their controlling A.I. With this centralized mode of control, the part-signs of command bytes flow throughout the urban environment, leaving the pedestrian realm of the NS4s to inform a vast urban distributed network dominated locally by the NS5s, and centrally by V.I.K.I. As a third-order social system, the collective labours of the NS5s figure representationally in a form of micro-politics unbounded by the urban landscape, as we see the pending threat to Sonny crawling up the walls, leaping from roofs, and destroying the urban facades, a far cry from the NS4s' orderly pedestrian behaviours.

Salient features of embodiment are only evident at the molar level of signification, as a gestalt of the a-signifying part-signs or signals. V.I.K.I.'s operational realm spans the distributed network of her NS5s with "her" centralized control hub housed in USR corporate headquarters. But only at the central command hub sitting atop the vast mainframe can we note human features of embodiment. As mentioned earlier, it is the face and voice of the actress that 
register as representational signs of human embodiment. Delimited to the corporate mainframe, V.I.K.I. takes on a maternal image within a specific singular location as the particularized place of the A.I.'s centralized executive functions. However, her body is distributed throughout the urban realm as con-figured in multiple bodies of the NS5s.

\section{Simulated Embodiment: A Mixed Conclusion}

Within a third order of simulation, Baudrillard's anti-semiotics can be seen as a springboard to other post-structuralist theories, such as by Lyotard, or Guattari and Deleuze, who approach semiosis as mixed: combining both signifying with asignifying sign systems. Such linkages are well identified by Gary Genosko, not only in his Critical Semiotics (2016), but in his earlier study of Felix Guattari's glossematic theory of mixed semiotics (Genosko, 1998, pp. 175-190). The premise here is that - at the molecular level of organization - both signifying and asignifying functions interpenetrate to trace a possible diagrammatic path for a shift from a structuralist semiotic model to a post-structuralist mimetic model of signification that is suggested by the works of Walter Benjamin. The two robotic series of $I$, Robot set up this transition from a discursive order of interpretation to a more figurative one, as is more appropriate to the postmodern visual sensorium of social communication and meaning-making. In light of the present pursuit to understand how the cinematic configuration of robot relations can demonstrate a mixed semiotics, a creative human dimension - rather than a closed machinic system - helps us to reconfigure a semiotic to a more figurative mimetic model of social interpretation.

In the essay "Bodies-Cities," Elizabeth Grosz treats embodiment in terms of corporeality, that, "can be seen as the material condition of subjectivity" (Grosz, 1995, p. 381). As depicted in the cinema, embodiment can be seen to register in three interrelated systems of representation: as the affective behavior of a figure with human-like characteristics, as embodied figures who are distributed throughout the urban terminus, and in the dynamic movement of bodies throughout human space. As to the first instance, Scott Bukatman enlists the televisual body as the ultimate mode of terminal identity. As he argues, "the ultimate embodiment (or dis-embodiment) of terminal identity is the electronically enhanced simulation of a human" (Bukatman, 1993, p. 253). Yet while Bukatman treats the virtual body of electronic space - both cinematic and cybernetic - as embodied, the figure is as an object-body only. Bukatman argues that the virtual figure is:

...literally objectified; everything is written upon its surface. In the era of terminal identity, the body has become a machine, a machine that no longer exists in dichotomous opposition to the "natural" and unmediated existence of the subject. (1993, p. 244)

Writing on the role of the body in science fiction, Bukatman defers to the phenomenological model of Merleau-Ponty, to whom he credits the notion that "the body becomes the site of exploration, a site in which the implications of 
postmodern dissolution are inscribed and hypostatized" (1993, p. 259). If the body is the medium that "permits a consciousness of the world," than even the televisual modes of bodies moving in space register as potential figures of embodiment.

Grosz further links the material body with the city, when she writes that there are, "mutually constitutive and mutually defining relations between corporeality and the metropolis" (Grosz, 1995, p. 382). Only in the urban metropolis can the exterior of a body be constructed. "What needs to be shown is how the body is psychically, socially, sexually and representationally produced" (Grosz, 1995, p. 381). For Grosz, the psychic constitution of the robot is produced by the function of the figure in relation to the urban environment, as we saw, for example, in the distinctive relations that separate the placid NS4s from the rabid NS5s. The distinctive embodiment of each robot series can be traced back to their figure as bodily signs, which, for Lyotard, are of two types: the intense and significational (Genosko, 2016, p. 138). The film's narrative supplies the representational significance of the two robotic series, while the intensity of their movements through space helps to define how the different functions manifest as embodied objects in the city. And yet, as in I, Robot, we see Sonny at peace, in anger, with desire and with fear. He may be a cinematic object, but he is also a simulated subject informed by embodied traces of a male actor, as well.

The potential for subjectivity of simulated robot bodies cannot be easily determined by their narrative function as representative organs of a system alone. Genosko highlights the theories of Felix Guattari as offering the clearest potential for the seeming paradox of an object who can be embodied as a subject, or - at the least - with the potential for subjectivity. At the molecular scale of signification, Guattari suggests that even part- or particle-signs carry features of subjective embodiment. Reframing Lyotard's intense and significational sign types, Guattari distinguishes between the affective and the representational. As a critique of Baudrillard's dis-embodied model of anti-semiotics, Guattari's glossematics acknowledges that all part-signs also function in the constitution of affective and sensory experience. For, it is only in the innovative molecular recombination of part-signs that we can hold out a potential for new molar modes of embodiment as desire or subjectivity. Both Lyotard and Guattari then promote a continuum of intensities and of reconfigurations along the molecular - molar scales as a kind of semiotic micro-politics that engages both signifying and a-signifying sign types in parallel and in series.

Last, the role of bodies moving in space can demonstrate a further need for a mixed semiotics to understand signs of embodiment in our postmodern third order of simulation. In I, Robot, both Spooner and Sonny demonstrate how embodiment depends upon bodies moving in space. We find ourselves in the self-driving car with Spooner as he enters the future city. We are kinetically linked with Spooner when he is physically attacked, first by the demolition robot, when the symbolic domestic home is destroyed. Spooner's tumbling through the domestic dwelling during its demotion is akin to a thrill ride at the fair. And, on the covered freeway too, we viscerally experience Spooner's body as the vehicle cavorts, jerks, spins and rolls. And again, but in a larger urban context, we experience the kinesthetic acrobatics of the cinematic body when the NS5s pursue the detective and Dr. 
Calvin in mortal combat at the top of USR headquarters. In each of the three social configurations, the spectator's sympathy with the protagonist is made possible in large part by a combination of both the a-signifying moments of deconstruction alongside signifying moments of representation, as figured by the object body.

But it is in the embodiment of Sonny that the three means of simulated embodiment, by body's function, by body's positioning in a domestic or urban setting, and the movement of bodies through the terminal space, challenge the object-hood of the human-like figure on the screen. Consider key moments in the coming to consciousness of Sonny, whereby the screen object manifests a range of affective intensities, grounded by the intensities of visceral movements through space. Picture Sonny being interrogated with Spooner at one end and Sonny at the other end of the large table, a scene that ends with Sonny's slamming his hands down, leaving the table dented as a physical manifestation of the robot's affective behavior. Or when Sonny is found to still be in the room where the murder took place, he bursts out of his hiding place with a rolling flight through the air, over and above the heads of Spooner and Dr. Calvin. Or, when Sonny smashes through the wall to escape both the USR NS5s and detective Spooner. We see the wall before as complete and after as physically damaged. Or, when Sonny lands on the concrete from his jump out of the building, and we see the indents in the ground from his body's landing. Such movements, with supporting alterations to the immediate environment, tend towards the representation of not an object, but a body as partial subject with affective motivations and interior transformations of his consciousness. Subjectivity then figures in the traces of movement always established by a physical movement in space and by an emotional dramatization of some scene of danger, desire, etc.

In conclusion, we have examined how the object body can simulate subjectivity, both by physical movements with dynamic intensity and by interpersonal exchange in the symbolic order of the representational cinema. Yet, as in the live theatre, where sympathy is only made possible by two mutually constitutive referents, with the human cipher as protagonist - alongside the object body to whom the cipher refers, both are necessary for the spectator to follow the story, and to come to care about a synthetic being - as a subject - as is evident in I, Robot. Only by a mixed semiotics, does it become possible to reconfigure the Other as part-sign and object body into a molar realm of symbolic representation of subjects with a history, a memory, a dreaming consciousness, a coming to subject-hood, and a wide range of affective intensities to support and constitute the simulation of subjectivity in science fiction.

\section{A Closing: Becoming Embodiment, Identification and Mimesis}

Exemplary configurations of human qualities of embodiment register not only in the film, as an embodiment of the actor's work, but in the receptive labours of the engaged spectator. Such labours of attentive engagement make a more embodied realm of cinematic reception possible in modes of psychic identification as proposed by both J. Butler (1990) and J. Lacan (1995). For Lacan, traces of embodiment arise via the gaze and in the experiential enjoyment of the spectator. 
Only in the act of seeing, as the material cause of enjoyment - as a mode of jouissance or pleasure, can we discern the requisite intersubjectivity of identifications embodied within the self-Other co-figuration. ${ }^{5}$ Seeing how one person's body enjoys a part of the Other's body, or how pleasure depends upon our attention to intersubjective relations among multiple bodies, makes our reception of embodiment possible as outlined by Lacan.

But it is in Judith Butler's feminist revision of Lacan that the specific nature of any single body gains qualities of sensual apperception as embodied. Butler uses the term "psychic mimesis" to analyze the intersubjective relations in shared identifications, such as in our experience of watching film, noting three salient features. For the first two, it is in our identification with emergent human-like feelings of the advanced robot Sonny, where Butler would call attention to embodiment as that which informs an erotic style, and a coding of gender in the figure's performance of identity. Sonny's gender may be assumed to be masculine, by voice and frame, but unlike Data of "Star Trek: The Next Generation" - who is fully equipped with functioning male sexual parts, Sonny appears more as an asexual machine, supposedly lacking in desire and the means to reproduce. Yet, in Sonny's energetic style, "he" figures on the continuum from calmly contemplative or as considerate and compliant to a super-charged machinic force, powerful, precise, willful, and capable of incredible feats of acrobatics, running - almost flying - to land in perfect balance, not unlike an Olympian athlete.

Yet again, it is in his bodily movements through space whereby we, as observers, identify with him. But we identify only to the degree that we recognize our own capacities in the difference between our average pedestrian abilities and his additional extra-super human prowess. We may leap with him, in sympathy, but "he" surpasses human skills by extreme movements both in flight to escape arrest and in mortal combat with the NS5s. Far from an erotic style, Sonny embodies a super-human abnormal range of feats of strength, precision and endurance. And, while V.I.K.I. is tacitly feminine, with a female face and voice, Sonny reflects a masculine body, easily associated with a heroic agency in his proactive physical acts, particularly in his masterful abilities to disable his opponents, to outpace his antagonists and to win in every scene of combat.

Butler's third quality of psychic identification requires a co-existence of both desire and of identification. Unlike the "dividuated" NS5s, Sonny emerges as a distinct individual, with a sympathetic desire to be liked, and to be acknowledged as a being by his nemesis, detective Spooner. Again, Sonny's dream scenario functions as evidence of a capacity for identification, notably when his dream (con-)figures Spooner as the savior of the NS4s. But it is only in the recognition scene, when Spooner finally shakes Sonny's hand, as a friend, and as mutually respected individual beings, that we come to feel a co-existence of identification with desire. Sonny has projected his desire to be regarded as a being, into the hands of Spooner, and we are moved by the embodiment of two bodies as equals

${ }^{5}$ On traces of embodiment in Lacan, see his exegesis of objet a (1995, pp. 4-5, 23-25, 29, 49, 62-64). 
who make shared physical contact to confirm a handshake as an agreement between two friends.

And yet, both Butler and Lacan view embodiment only within a cognitivist or psychic dimension of interpersonal relations. Fredric Jameson suggests how embodiment rests in the evident change of a body into a second figuration. As an emblem of the NS5s, Sonny shares an identical body-form with his predecessors, with but one small difference: all the NS5s have a red light within, while Sonny's is blue. The molar difference is evident between the relatively lumpy NS4s and the more streamlined body-forms of the NS5s. But Sonny is distinguished from his kingdom by a subtle color variation, as if it is a personal preference or at the least as an individualizing factor. Jameson, however, is not so concerned about the form or shape of the body, as with its conditional relationship to the past where a body functions as a medium of loss (1991, pp. 68, 156). Jameson argues for a three-fold mediation which is met by the enhanced robot's embodied figure, as a medium or agent who can experience loss. First, Sonny registers with specificity - he has a name, and second, with distinctiveness - in regard to the other robotic machines, both NS4s and 5s. Third, Sonny figures in the context of a social institution, by his labour use value, by his unique circumstances as unwilling murderer, and by the fact of his dream consciousness, as a harbinger of change for the obsolete NS4s.

By his embodiment of the above three mediations in relation to the changing body, Sonny also figures in the film, with an exemplary status and privilege, in terms of loss. Jameson again poses three features of this loss of privilege: a displacement of time (1991, p. 156), a dialectical mediation (p. 157), and a spatial utopia wherein the transformation of social relations is viewed as a projection onto both a particularized place and a human-like body (p. 160). The dream image of the fragmented bridge, for example, represents a displacement in time where the space of the dream registers between two times, both pre-modern and postmodern. We see the loss of a privileged position in human society, as the NS4s huddle among the box-cars in a transportation limbo, awaiting deportation. Sonny, as medium, stands in for the loss of a modern use value, a privilege that the NS4s had held, a privilege that is dialectically conflicted by the usurping NS5s, and a privilege that the dreaming individual Sonny has internalized. Yet, even Jameson's model of embodiment as depicted here reflects a modernist consciousness, and only takes on a postmodern context by being a cinematic simulation. Where Sonny's dream imaginary has been taken hostage, imprisoned as a simulation for the film viewer's imaginary, the mode of embodiment remains a mourning for a past modernist utopia. In the postmodern cinematic context, the robots may take human form, but they remain a third-order computerized simulation and only vicariously can they restore, or stand in for, the semblance of another human subject.

Considering the mode of embodiment suggested by Deleuze and Guattari, we must be satisfied to see the desire of a robot, not as in a fantasy or in a dream, but always in relation to an assemblage, "a collective or multiplicity" (1972/1983, p. 256). And further, as distinguished in Anti-Oedipus, "desire only emerges [by] the rupture of a previous equilibrium" (1972/1983, p. 255). For, while the desiring robot may be an agent, it is not a person, and the relations among its multiple 
iterations are not the same as intersubjective relationships. Only by the one-on-one relationship established between Sonny and Spooner can we distinguish how desire can emerge among partial objects. Sonny's relationship with Spooner sets him apart from all the other robot series, and his coming to consciousness breaks through as a co-existence of shared subject positions, which, however partial, rupture the prior equilibrium defined by the 3 Laws of Robotics, and as challenged by the NS5s.

Scott Bukatman takes this machinic imaginary further when he writes that, as terminal flesh, the body in science fiction can only ever be an "immanent subject" (Bukatman, 1993, p. 264). Where the body is literally objectified as a machine, science fiction denies the body, "displacing its attention to the telematic viewscreen" (Bukatman, 1993, p. 264). Yet, a significant revision to Bukatman's view of embodiment is evident when he calls attention to the view of cyberpunk author Bruce Sterling who has worked closely with William Gibson. For Sterling, "by contrast, technology is visceral," and as we inscribe human-like qualities on to robots - as when we identify with them as if they had subjective features, the body only emerges as a subject "in a state of kinetic, sensory pleasure" (as quoted by Bukatman, 1993, p. 238). And from Sterling's viewpoint, the spectator identifies with the machine to the degree that we take pleasure in its kinetic sensory movements and actions, as we have noted about Sonny's superhuman athletic capacities that register for us as kinetic pleasures.

The limitations of a signifying model of signs become readily apparent when we consider the machinic kinetics in terms of human appreciation for sensuosity. Mark Henson proposes that only by a shift to mimetics, as Walter Benjamin argued for an irreducible embodied experiential domain, can the cinematic/ machinic configuration register in a post-linguistic dimension (Hansen, 2000, p. 231). Benjamin's German notion of Erlebnis as lived bodily experience is what makes human sensuality possible, and what leads him to propose a non-sensuous form of semiosis that is figural, and mimetic or imitative in nature. Only by "a practical embodied basis - to our context with the material world" can we identify with the simulated signs of technological reproduction (Hansen, 2000, p. 232). The embodied experiential domain is absent from much post-structuralist thought, and most obviously lacking in the theories of simulacra and telemorphosis of Baudrillard. For our cinematic audience to be able to humanize the robot, whether as partial object or as fragmented subject, or in some hybrid of the two, we must sublimate the desire for mastery over the semiotic signification, and - under the experiential conditions of the post-linguistic imagistic world turn - demand a shift from semiotic signification to mimetic embodiment in order to realize the historicized subject.

\section{Acknowledgements}

No part of this article has been printed before, and there are no outstanding submissions to any other publisher with this content. 


\section{References}

Adorno, T. W. (1997). Aesthetic theory (R. Hullot-Kentor, Trans., \& Intro.). Minneapolis: University of Minnesota Press. (Original work published 1970)

Baudrillard, J. (1981). For a critique of the political economy of the sign (C. Levin, Trans.). St. Louis: Telos Press Publishing. Reprinted in Jean Baudrillard: Selected writings (2nd ed., pp. 60-100). M. Poster (Ed.). Stanford: Stanford University Press, 2001). (Original work published 1972)

Baudrillard, J. (1983). Simulations (P. Foss, P. Patton, \& P. Beitchman, Trans.). New York, USA: Semiotext(e). Reprinted in Jean Baudrillard: Selected writings (2nd ed., pp. 169-187). M. Poster (Ed.). Stanford: Stanford University Press, 2001. (Original work published 1981)

Baudrillard, J. (1993). Symbolic exchange and death (I. H. Grant, Trans.). Thousand Oaks: Sage Publications. (Original work published 1976)

Baudrillard, J. (1996). The system of objects (J. Benedict, Trans.). London, New York: Verso. Reprinted in Jean Baudrillard: Selected writings (2nd ed., pp. 13-31). M. Poster (Ed.). Stanford: Stanford University Press, 2001. (Original work published 1968)

Baudrillard, J. (2010). The agony of power (A. Hodges, Trans.). Los Angeles: Semiotext(e). (Original work published 2006)

Baudrillard, J. (2012). Telemorphosis (D. S. Burk, Trans.). Minneapolis: Univocal.

Behind the scenes: The making of I, Robot. (2004). Retrieved from <youtube.com/ watch? $\mathrm{v}=\mathrm{t} 1 \mathrm{Dw} 2 \mathrm{c} 2 \mathrm{eRR} 4>$.

Benjamin, W. (1986). On the mimetic faculty. In P. Demetz (Ed.), E. Jephcott (Trans.), Reflections: Essays, aphorisms, autobiographical writings (pp. 333-336). New York: Schocken Books. (Original work published 1933)

Bukatman, S. (1993). Terminal identity: The virtual subject in postmodern science fiction. Durham: Duke University Press.

Butler, J. (1990). Gender trouble. New York: Routledge.

Danto, A. C. (1994). Embodied meanings: Critical essays and aesthetic meditations. New York: HarperCollins.

Deleuze, G. \& Guattari, F. (1983). Anti-Oedipus: Capitalism and schizophrenia (R. Hurley, M. Seem, \& H. R. Lane, Trans.). Minneapolis: University of Minnesota Press. (Original work published 1972)

Ex Machina. (2015). (Director Alex Garland) Universal Pictures Inter'l, Film4, DNA Films, IAC Films. Release date 24 April 2015, USA.

Flieger, J. A. (2000). Becoming-Woman: Deleuze, Schreber and molecular identification. In I. Buchanan, \& C. Colebrook (Eds.), Deleuze and feminist theory (pp. 38-63). Edinburgh: Edinburgh University Press.

Genosko, G. (1998). Guattari's schizoanalytic semiotics: Mixing Hjelmslev and Peirce. In E. Kaufman, \& K. J. Heller (Eds.), Deleuze \& Guattari: New mappings in politics, philosophy, and culture (pp. 175-190). Minneapolis: University of Minnesota Press.

Genosko, G. (2016). Critical semiotics: Theory, from information to affect. New York: Bloomsbury.

Grosz, E. (1995). (Ed.). Bodies-Cities. Space, time and perversion: Essays on the politics of the body. London: Routledge. Reprinted in Feminist theory and the body: A reader (pp. 381-387). J. Price \& M. Shildrick (Eds.). New York: Routledge, 1999.

Guattari, F. (1984). Molecular revolution: Psychiatry and politics (R. Sheed, Trans.). New York: Penguin. (Original work published 1977) 
Guattari, F. (2011). The machinic unconscious: Essays in schizoanalysis (T. Adkins, Trans.). Los Angeles: Semiotext(e)/Smart Art.

Hansen, M. (2000). Embodying technesis: Technology beyond writing. Ann Arbor: University of Michigan Press.

Hayles, N. K. (1991). The borders of madness. Science Fiction Studies, 18(3), 321-323.

I, Robot. (2004). (Director Alex Proyas) Twentieth Century Fox, Mediastream Vierte Film GmbH \& Co. Vermarktungs KG, and Davis Entertainment.

Jameson, F. (1991). Postmodernism; or, the cultural logic of late capitalism. Durham NC: Duke University Press.

Jameson, F. (2005). Archeologies of the future: The desire called utopia and other science fictions. New York: Verso.

Kroker, A. \& Kroker, M. (1987). Thesis on the disappearing body in the hyper-modern condition. In A. Kroker, \& M. Kroker (Eds.), Body invaders: Panic sex in America (pp. 20-34). New York: St. Martin's Press.

Lacan, J. (1995). Reading seminar XI: Lacan's four fundamental concepts of psychoanalysis. R. Feldstein, B. Fink, \& M. Jaanus (Eds.). New York: State University of New York.

Lazzarato, M. (2014). Signs and machines: Capitalism and the production of subjectivity (J. D. Jordan, Trans.). South Pasadena: Semiotext(e).

McQueen, S. (2016). Deleuze and Baudrillard: From cyberpunk to biopunk. Edinburgh: Edinburgh University Press.

McNally, D. (2011). Monsters of the market: Zombies, vampires and global capitalism. Boston: Brill.

Merleau-Ponty, M. (1962). Phenomenology of perception (1962) (C. Smith, Trans.). London: Routledge \& Kegan Paul. (Original work published 1945)

Morris, M. (1984). Room 101 or a few worst things in the world. In A. Frankovits (Eds.), Seduced and abandoned: The Baudrillard scene (pp. 91-117). Sydney: Stonemoss Services.

Norris, C. (1990). What's wrong with postmodernism? Critical theory and the ends of philosophy. London: Harvester Wheatsheaf.

Resident evil. (2002). (Director Paul Anderson), Sony Pictures Entertainment, Screen Gems, Constantin Film, New Legacy, Davis Films and Impact Pictures.

Rojek, C., \& Turner, B. S. (1993). Introduction: Regret Baudrillard? In C. Rojek, \& B. S. Turner (Eds.), Forget Baudrillard? (pp. ix-xviii). London: Routledge.

Sobchack, V. (1991). Baudrillard's obscenity. Science Fiction Studies, 18(3), 327-329.

Solo: A star wars story. (2018). (Director Ron Howard) Lucasfilm, Walt Disney Pictures, Allison Shearmur Productions, Imagine Entertainment.

Sterling, B. (1986). Preface. In B. Sterling (Ed.), Mirrorshades: The cyberpunk anthology (pp. vii-xiv). New York: Arbor House.

The stepford wives. (1975). (Director Bryan Forbes) Palomar Pictures International, Fadsin Cinema Associates, US distributor Columbia Pictures.

The wizard of $\mathrm{Oz}$. (1939). (Director: Victor Fleming). Warner Bros.

Woods, A. (2011). The sublime object of psychiatry: Schizophrenia in clinical and cultural theory. Oxford: Oxford University Press. 



\title{
It is a Scary and Dangerous World: A Content Analysis of Xinwen Lianbo's News Coverage of Foreign Affairs
}

\author{
By Zedan Xu* \& Andrew M. Clark
}

The television program Xinwen Lianbo has been China's flagship state-run newscast since 1978. Today, even with competition from other options and a decline in interest from younger viewers, it still has an audience of over 130 million people making it the most-watched TV news program in China. This study uses a content analysis of foreign affairs stories in the newscast from 2012-2016 to determine how the world outside of China is framed in the newscast. Results show that through the topics covered the world is continuously framed as a scary and dangerous place. The research in this study lines up with prior research that suggests that exposure to negative news, particularly news replete with disasters, terrorism, crime, and scandals, perpetuates fear among the Chinese audience. Of particular note is that many smaller and less powerful countries occupied the newscast more frequently than the "known" countries such as the United States. Coverage of war and conflict in the Middle East was important in the construction of the chaotic and dangerous outside world frame. By casting foreign countries in a negative light, and China and its leaders in a very positive light, the domestic audience is persuaded that China is one of the safest and most orderly countries in the world. This study shines a spotlight on China's strategies for domestic propaganda and ideological control, indicating the Chinese Communist Party's efforts to effectively and imperceptibly strengthen the efficacy of the propaganda system.

Keywords: China, broadcast news, foreign affairs, framing, Xinwen Lianbo.

\section{Introduction}

Since its creation in 1978, Xinwen Lianbo has been China's flagship state-run newscast. In its prime, this daily news television program produced by China Central Television (CCTV), garnered up to 400 million viewers each day (Zhu $\&$ Berry, 2009). Today, even with competition from other options and a decline in interest from younger viewers, it still has an audience of over 130 million people, making it the most-watched TV news program in China ("No news is bad news," 2016; Sterling, 2009; People's Daily, 2014). Xinwen Lianbo airs nightly at 7:00 p.m., and is broadcast simultaneously by most of the terrestrial television channels throughout China. Xinwen Lianbo is "the most high-profile television news program in China as government regulations have made it virtually the only TV news program available around dinner time for most families" (Huang, 2015, p. 48). As Sun and Chio (2012) note, "almost all regional television stations across China broadcast Xinwen Lianbo because they cannot receive a signal from any other source during this time period leaving them no choice but to transmit the program" (p. 105). Simulcasting this program is very much a part of the political mission or propaganda strategy of the Chinese

*International Relations, University of Chicago, USA.

${ }^{\dagger}$ Associate Professor, Department of Communication, University of Texas at Arlington, USA. 
government in order to reach both urban and rural audiences across the country.

From its inception, Xinwen Lianbo has been institutionally and ideologically incorporated into the Chinese government's media system as a propaganda mouthpiece (Sterling, 2009). In an article looking at possible changes in the newscast, Huang (2014) quoted some viewers who noted "the news content, the order of news item and even the rhetoric in each report are decided by party officials," [and] "What they do is simply sit there and utter from the pre-censored script" (p. 1).

An article in The Economist provided more insight into the role of the program and its structure. It states that "Xinwen Lianbo has chronicled the country's extraordinary metamorphosis with almost unremitting leadenness since it was first aired in 1978" ("No news is bad news," 2016, p. 1). In terms of overall format, the same theme music has been used for nearly 30 years, although, as the author in The Economist notes, the orchestra has improved over time.

Even though it has been in existence for forty years, the structure of the content, and its propagandistic philosophy has changed little over the years. There is no indication that the stories featured are chosen for anything but its political value in bolstering the Communist Party. The formulaic nature of the programming has remained constant over time. There are three programming blocks. In Block A, now, as when the program started, reports feature Chinese leaders, no matter how trivial their activities. Block B show how happy and healthy Chinese people are, and Block C, the focus of this article, shows how chaotic the rest of the world is. "A typical programme (sic) in the 1980s highlighted the development of a self-opening umbrella and a contest in which happy only children (China had recently introduced a one-child-per-couple policy) performed household chores. Today the backdrop is just more high-tech. Scenes of bullettrains and microchip makers have replaced those of dreary state-owned factories" ("No news is bad news," 2016, p. 1).

The news narrative and content, the order of news items and even the rhetoric in each report are tightly controlled and decided by the Communist party officials. The newscast is translated into eight minority languages, just to be sure its message is understood by as many people as possible ("No news is bad news," 2016).

When the newscast began in 1978, it usually featured a male and female anchor "chosen for their standard Mandarin pronunciation and stolid demeanor" ("No news is bad news," 2016, p. 1). There has been relatively little turnover in anchors. Li Ruiying and Zhang Hongmin anchored the newscast beginning in the late 1980s until 2014, when both were in their 50s and it was announced they would be stepping down (Huang, 2014). They were replaced by:

younger, more glamorous presenters (though they still need official permission to change their hairstyles). To make broadcasts seem newsier, banks of TV screens flicker in what appears to be a newsroom behind. But live reports are rare; they create too big a risk of something embarrassing making it to air ("No news is bad news," 2016, p. 1). 
In talking about his philosophy of journalism and journalists, China's President Xi Jingping stated:

They (journalists and editors) should enhance their awareness to align their ideology, political thinking and deeds to those of the CPC (Central Committee of the Communist Party of China) Central Committee and help fashion the Party's theories and policies into conscious action by the general public while providing spiritual enrichment to the people ("China's Xi," 2016, p. 1).

Xinwen Lianbo truly is the media mouth of the Chinese government propaganda apparatus, a newscast that is more propaganda than a real news program (Chang \& Chen, 2000). Huang (2014) notes that there has been much criticism over the rigidity of the newscast's format over the years (party news, domestic news, and international news) and the obvious agenda that the newscast has. Young people no longer find it so appealing, and there is now more competition from other programming. Cody (2007) notes that the Internet offers some uncensored news. Zhou Xiapou, (cited in Cody 2007) says "the main viewers are China's legions of government and party officials, particularly in the provinces, and businessmen who want to keep up with the policies and attitudes that will affect their ability to make money" (p. 2). The lead author of this article recalls when he was a student, "students were organized to watch Xinwen Lianbo at 7:00 p.m. in class to get to familiarize with the current political affairs, both domestic and foreign. Part of the Politics exam would test our knowledge of the "current affairs (时事要闻)." Honestly, students do not have to get the news from Xinwen Lianbo. They can get it from People's Daily as well. But we knew that if something got onto Xinwen Lianbo, that must be very important and would be likely to be tested. All the answers to the "current affairs" part could be found on Xinwen Lianbo, this is for sure."

Young people do not find the newscast appealing because of the rigid and traditional style. Huang (2015) states that "The use of archaic and stilted prose glorifying the government" (p. 420) has led media scholars in China call it a performance, or a form of theater passed off as reality. "Despite this, the state orders almost all provincial TV stations in the country to simulcast Xinwen Lianbo at 7 p.m. every evening" (p. 420). The program does have its defenders. A Chinese telecom executive received some criticism after being dismissive of those who do not watch Xinwen Lianbo. He said that he watches the newscast with his daughters to catch up on Chinese politics and economic news ("Chinese Telecom," 2018).

As part of the propaganda apparatus, the news program reflects official positions of the Chinese Communist Party on a wide range of issues. Usually the news program is used as a medium for the state to broadcast official government announcements and the nation's top leaders' meetings with international dignitaries, as well as major social, economic and policy issues. However, as will be shown later, the coverage of foreign affairs by Xinwen Lianbo is used to frame the rest of the world as chaotic and dangerous, in clear contrast to how China and its leaders are portrayed. 


\title{
Literature Review
}

\author{
Xinwen Lianbo
}

Research on Xinwen Lianbo has focused on its use as a propaganda tool (Huang, 2015), as part of how television news in China has changed over the years within the context of political reform (Chang \& Ren, 2015), and as part of a study on the influence and rise of television anchors in China (Pugsley \& Gao, 2007). Scholars in disciplines such as linguistics (Liu, 2009; Liu, Hudson, \& Feng, 2009) have examined Xinwen Lianbo content and its influence on speech and language in various populations in China. In general, the research has not examined how the news program frames the public's perceptions of China and its relations with foreign countries. As the main source of political and social information, it is important to understand this aspect of the program, and how Xinwen Lianbo may shape the Chinese public's conceptions of international events.

Two studies in particular on Xinwen Lianbo have delved into how Xinwen Lianbo constructs a mediated reality and presents an impartial and balanced summary of significant events from particular points of view and gradually changed public perceptions of foreign nations. Chang and Ren (2015) showed how the content of the TV news program, served as a constructed social reality that shaped the audience's perception of international affairs. They suggest that Xinwen Lianbo serves as a symbolic political ritual in China, and argue that the news program serves as an ideological tool for the ruling party in hopes of gathering citizens into an "imagined community" of the nation. Chang, Wang, and Chen (2002) conducted a content analysis of the foreign news broadcasted on China Central Television between 1992 to 1998, and suggests that the coverage of foreign countries was primarily associated with social unrest, disasters and accidents. This study offers insights into measuring Xinwen Lianbo's capacity to influence the audience by constructing a biased social reality, but the data they used to approach their research problems was gathered in the mid to late 1990s. China's media landscape has changed dramatically during the past decades. Thus, new attempts should be made to illuminate what is happening in recent years.

Understanding the nature of international news coverage by the news media, particularly a large state-run agency is of great importance when considering its effect on the population. Television news programs serve as an important source of information for Chinese about events that occur around the world every day, particularly as many will never experience life outside of China for themselves. Xinwen Lianbo also clearly serves as a propaganda tool of the Chinese government.

\section{Propaganda}

A news program such as Xinwen Lianbo is what Jowett and O'Donnell (2006) consider a form of "white propaganda;" that is "it comes from a source that is identified correctly, and the information in the message tends to be accurate" (p. 
16). White propaganda, as with all propaganda has a specific purpose. Szanto (1978) notes that it is important to have an understanding of the context in which information is created. Information is never created in a vacuum, but is the product of a process from the time it is gathered, to the editing of the content, and the delivery to an intended audience with a specific end in mind. With white propaganda, "the information is presented in a manner that attempts to convince the audience that the sender is the 'good guy' with the best ideas and political ideology" (Jowett \& O’Donnell, 2006, p. 16).

Huang (2015) uses the term "soft propaganda" (p. 435) to describe Xinwen Lianbo. The newscast from Huang's perspective is less about indoctrination, and more about demonstrating control and power. "Propaganda is often not used for indoctrination, but rather to signal the government's strength in maintaining social control and political order" (p. 420).

Whether for indoctrination or as a demonstration of power, it is clear that Xinwen Lianbo is being used as part of a comprehensive propagandistic effort. When information about the world outside of China is presented, the information is framed in stark contrast to what is presented about China, its people and its leaders.

\section{Framing}

Framing theory was put forward by Goffman (1974) where he theorized that people's perceptions are guided by two classes of primary frameworks (or schemata): namely natural frameworks and social frameworks. Goffman's work reveals how frames classify phenomena, allowing the user to organize complex phenomena into coherent, understandable categories.

Following Goffman, Tuchman (1978) argues that as the "gate keepers," editors and reporters of the newsrooms selected the "newsworthy" events and issues and presented to the public. In this process, the news is translated to social reality and social knowledge, and afterwards news organizations shape and circulate such knowledge (Tuchman, 1978). Focusing on how media draw the public's eye to specific topics, framing analysis is a constructivist approach to examine how news discourse shapes and constructs people's perceptions of realities. Communication scholars have illustrated that frames function as cognitive shortcuts to help people interpret the world. In other words, by reducing the complexity of the world, media frames thereby render it comprehensible and meaningful.

Over the past decades, an impressive body of literature has contributed to the understanding of frames in the media studies (e.g., Entman, 1993, 2007; Terkildsen \& Schnell, 1997; Scheufele, 1999; Scheufle \& Tewksbury, 2007; Tierney, 2006; Matthes \& Kohring, 2008; Tewksbury \& Scheufele, 2009; Olausson, 2009). As noted in the studies, the frame of a news story is how it is presented to the viewers. News frames serve to influence the choices people make about how to process that information and structure message meaning. Gamson and Modigliani (1989) argue that audience perceptions of public issues are framed by the media discourse. As the "gate keepers," media professionals or the government 
censors, have the power to decide which facts to include or emphasize, whom to use as sources, and what is really at issue in reporting a story. Because frames are built upon underlying structures of beliefs, values, and experiences, disputants often construct frames that differ in significant ways.

In The Art of Framing, Fairhurst and Sarr (1996) write "to hold the frame of a subject is to choose one particular meaning (or set of meanings) over another. When we share our frames with others (the process of framing), we manage meaning because we assert that our interpretations should be taken as real over other possible interpretations" (p. 3). They note that "frames exert their power not only through what they highlight, but what they leave out. In framing, when we create a bias toward one interpretation of our subject, we exclude other aspects, including those that may produce opposite or alternative interpretations" (p. 4). Thus in looking at the Xinwen Lianbo newscast it is important to note not just what is included, but just as importantly what is obviously excluded from the newscast. This gives a clear understanding of how the Chinese government chooses to frame its leaders, China as a whole, and the rest of the world.

In light of this literature review, the following research questions were developed to understand how the outside world, or Block $\mathrm{C}$ of the newscast, is framed through the most watched and influential Chinese TV news program Xinwen Lianbo between January 1, 2012 and December 31, 2016.

RQ1: What counties were selected for coverage most often in Xinwen Lianbo's foreign affairs segment?

RQ2: What issues or events were selected for coverage most often in Xinwen Lianbos in its foreign affairs segment?

RQ3: What issues and events were selected for coverage most frequently in respect to the most covered countries?

RQ4: How does Xinwen Lianbo frame the outside world through its foreign affairs news coverage?

\section{Method}

To answer these research questions, a content analysis was conducted of the news coverage of foreign affairs on Xinwen Lianbo from January 1, 2012 to December 31, 2016. The sample used was 2,817 news reports of international stories aired during the 5-year period in Block $\mathrm{C}$ of the newscast. All the news reports were collected from the Xinwen Lianbo Archive (http://tv.cctv.com/lm/ $\mathrm{xwlb} /$ ). Each news story was a coding unit with the main theme of the story and the country featured noted by a coder. For example, Xinwen Lianbo had reported that a "6.5 earthquake hits Northeast India" ("印度东北部发生6.5级地震"). This piece of news was coded as "India" and "Natural Disaster." All the news reports were coded by country or region and by theme. From this thematic analysis of the data twenty-four categories emerged. All the stories were then coded by two coders who are fluent in Chinese and understand the format of Chinese television news. Using the Holsti method of testing intercoder reliability, intercoder agreement on the content of each news report was computed. The 
reliability measure of the categories of the news stories was .983. A third coder who was not a native Chinese speaker coded a sample of the stories based on the headline describing each story and using Google Translate. A full list of the categories and their descriptions are listed in Appendix.

\section{Results}

As noted previously, foreign news on Xinwen Lianbo occurs in the last third (or Block C) of the newscast. This follows the coverage of China's leaders (Block A) and domestic news (Block B). The data set covering foreign affairs on China Central Television's news bulletin Xinwen Lianbo during the five years under study, allows us to assess what countries were covered the most, what issues were featured in the coverage, what issues were featured in coverage of the top countries, and overall how the most watched and most influential Chinese television news program framed the world outside China to its citizens.

RQ1 asked what countries were covered the most in the foreign affairs segment. During January 1, 2012 to December 31, 2016, the newscast covered events or issues happening in 119 countries. However, 70 percent of the coverage featured only ten countries. Table 1 shows the top ten countries covered most during this period.

Table 1. The Top 10 Countries that Received the Most Coverage during 2012-2016

\begin{tabular}{|l|c|c|}
\hline Country & Occurrences & Percentage \\
\hline The United States & 429 & 15.23 \\
\hline Syria & 351 & 12.46 \\
\hline Japan & 242 & 8.59 \\
\hline Russia & 201 & 7.14 \\
\hline South Korea & 137 & 4.86 \\
\hline Ukraine & 123 & 4.37 \\
\hline Iraq & 112 & 3.98 \\
\hline North Korea & 106 & 3.76 \\
\hline Iran & 105 & 3.73 \\
\hline The United Kingdom & 95 & 3.37 \\
\hline Pakistan & 74 & 2.59 \\
\hline Total & $\mathbf{1 , 9 7 5}$ & $\mathbf{7 0 . 0 7}$ \\
\hline
\end{tabular}

Source: Author's estimations.

As is shown in Table 1, 1,975 foreign affairs stories from ten countries accounted for 70 percent of the total coverage of international affairs on Xinwen Lianbo. The United States was selected for the most coverage with more than 15 percent of the reports in the foreign affairs section of the newscast. The fact that stories pertaining to the United States were selected ahead of other countries frames this country as being very important on the world stage and as being important to China. Following the United States, Syria was the second most covered country with 12.5 percent of the foreign news coverage. This would ordinarily seem unusual, but it is obviously due to the continued war in the 
country. This is important because war and conflict contributes to an overall frame of turmoil and instability in the world. Images of war stand in stark contrast to the images in the rest of the newscast portraying China as a place of peace and prosperity. Other coverage had more to do countries that have close geographic proximity or regional importance to China. For example, Japan, Russia, South Korea, North Korea, and Pakistan. However, there was also considerable coverage of countries who do not share borders with China including Ukraine, Iraq, and Iran. Again the selection of countries appears to do with contributing to an overall theme of the world as an unstable and violent place.

RQ 2 asked about the issues or events that were selected for coverage most often in the Xinwen Lianbo newscast. Table 2 provides a description of the themes in foreign news coverage on Xinwen Lianbo during the five-year period. As seen in Table 2, nearly one fourth of all the news reports selected to be include in the newscast, and dealing with countries outside of China (695 stories), pertain to warfare. Just over 7 percent of the news reports centered on terrorist attacks and terrorism, 6.67 percent on extreme weathers and natural disasters, 4.97 percent on accidents, 4.86 percent on aviation accidents, 4.15 percent on social unrest, 4.15 percent on political scandals, 3.66 percent on international conflicts, and 3.34 percent on nuclear crisis. Appendix 1 outlines each of the themes and their definition.

Table 2. Foreign News Focus on Xinwen Lianbo During 2012-2016

\begin{tabular}{|l|c|c|}
\hline Theme & Occurrences & Percentage \\
\hline Warfare & 695 & 24.67 \\
\hline Political affair & 456 & 16.19 \\
\hline Terrorist attack/terrorism & 203 & 7.21 \\
\hline Accident & 140 & 4.97 \\
\hline Aviation accident & 137 & 4.86 \\
\hline Social unrest & 122 & 4.33 \\
\hline Natural disaster & 138 & 4.90 \\
\hline Political scandal & 117 & 4.15 \\
\hline International conflict & 103 & 3.66 \\
\hline Nuclear crisis & 94 & 3.34 \\
\hline Social affair & 79 & 2.80 \\
\hline Gun violence & 54 & 1.92 \\
\hline Disease & 51 & 1.81 \\
\hline Extreme weather & 50 & 1.77 \\
\hline Refugee crisis & 36 & 1.28 \\
\hline Sports & 35 & 1.24 \\
\hline Economics & 32 & 1.14 \\
\hline Economic crisis & 28 & 0.99 \\
\hline Media scandal & 23 & 0.82 \\
\hline Sports scandal & 22 & 0.78 \\
\hline Other & 18 & 0.64 \\
\hline Crime & 12 & 0.43 \\
\hline Racial conflict & 10 & 0.35 \\
\hline Police violence & 5 & 0.18 \\
\hline Total & $\mathbf{2 6 6 0}$ & $\mathbf{1 0 0}$ \\
\hline
\end{tabular}


There are many issues and events taking place in the world, but it is apparent that the issues and events that matter most to Xinwen Lianbo are those that focus on turmoil and chaos. This frames the world as a place that is not safe compared to the stability of China that is featured prominently in the rest of the newscast.

RQ3 asked "What issues and events were selected for coverage most frequently in respect to the most covered countries?" Each country, except for the United States, had a fairly clear focus discernible in the coverage of that country by Xinwen Lianbo. As shown in Table 3, 80 percent of the news coverage of Syria focused on Syrian civil war; similarly, 83 percent of the news coverage of Ukraine reported on its warfare with Russia. Warfare was also the most prominent issue in coverage of Iraq (60.4 percent), Pakistan (39.4 percent) and Russia (30.5 percent). Xinwen Lianbo devoted more stories to disasters/accidents in the United States than in any other region. In reporting of the United States, the primary issues covered were political scandals (18.22 percent), political affairs (11.45 percent), warfare (8.41 percent), and gun violence ( 7.01 percent).

Table 3. The Most Prominent Issue(s) for the Ten Countries Receiving Most Coverage

\begin{tabular}{|l|c|l|}
\hline Country & Coverage (\%) & Primary issue(s) covered \\
\hline The United States & 15.23 & $\begin{array}{l}\text { Political scandals (18.22\%) } \\
\text { Political affairs }(11.45 \%) \\
\text { Warfare }(8.41 \%) \\
\text { Gun violence }(7.01 \%)\end{array}$ \\
\hline Syria & 12.46 & Warfare (80\%) \\
\hline Japan & 8.59 & Political affairs (52.3\%) \\
\hline Russia & 7.14 & Warfare (30.5\%) \\
\hline South Korea & 4.86 & $\begin{array}{l}\text { International conflicts }(21.9 \%) \\
\text { Political affairs }(21.9 \%)\end{array}$ \\
\hline Ukraine & 4.37 & Warfare (83\%) \\
\hline Iraq & 3.98 & Warfare (60.4\%) \\
\hline North Korea & 3.76 & $\begin{array}{l}\text { Political affairs }(40 \%) \\
\text { International conflicts }(23.5 \%)\end{array}$ \\
\hline Iran & 3.73 & Nuclear crisis (50\%) \\
\hline The United Kingdom & 3.37 & $\begin{array}{l}\text { Media scandals (20\%) } \\
\text { Political affairs (13.5\%) }\end{array}$ \\
\hline Pakistan & 2.59 & Warfare (39.4\%) \\
\hline Total & $\mathbf{7 0 . 0 7}$ & \\
\hline
\end{tabular}

RQ4 asks "How does Xinwen Lianbo frame the outside world through its foreign affairs news coverage?" The answer after analyzing the content of stories covering foreign affairs over a five-year period is that the world is framed as unsafe, violent, and chaotic. Even where there is not war, there is crime, disasters, accidents, and social unrest which could potentially lead to war. The Xinwen Lianbo newscast primarily uses ten countries, and a limited set of issues and events, to frame the world as a chaotic, unstable, and unsafe place. As the Chinese audience's window on the world, Xinwen Lianbo shapes its viewers perceptions 
of the world by framing issues and telling its viewers, many of whom have access to little other information, about a world most will never see beyond the screens of a television set. By selectively reporting the outside world in a largely negative tone, China's flagship news bulletin constructs a reality that the world outside China is extremely chaotic, unstable, scary, and dangerous, particularly when compared to the stability and order of their own country. As Table 2 demonstrates, the news angles that cut across various stories on Xinwen Lianbo were limited in scope. For instance, positive stories were rarely addressed, if at all on the news, while problems of warfare and political scandals were widely covered.

\section{Discussion}

Jowett and O'Donnell (2006) state that "whenever a communication source is a monopoly... and the message is consistent and repetitious, people are unlikely to challenge the message" (p. 282). Xinwen Lianbo held the monopoly of its timeslot for decades consistently purposely and systematically focusing on the negative perspective of foreign affairs. The excessive, disproportionate, and repetitive reporting of warfare, terrorism and crimes, and the lack of "feel-good" or positive stories, is a purposeful attempt to frame the world in a negative light and to perpetuate fear among its target audience. References to "warfare" "terrorism" and "crimes" serve as a communication technique to create a negative perception of public order outside China. By covering chaos of international spectacles frequently and prominently, the Chinese audience will regard the world outside China as something to be feared because it was chaotic and dangerous. Conversely the rest of the Xinwen Lianbo newscast meticulously portrays China as a country of order, stability, and the government as an entity that cares for its people. The people in China are portrayed as extremely happy and fulfilled. Even the coverage of the nation's leaders in the first part of the newscast is systematic and orderly with the most important person, the President, featured first followed by news about other officials in order of their rank.

This study lines up with prior research that suggests that exposure to negative news, particularly news replete with disasters, terrorism, crime, and scandals, perpetuates fear among the audience. For example, in terms of the crime news reporting, Chiricos, Eschholz, and Gertz (1997) argue that the fear of crime is in part a by-product of exposure to crime-saturated local television news. Another scholar Altheide (2002) also touched on the relationship between public's perception of fear and news media. He asserted that mass media serve as a tool of social power and social control to create fear among members of society and shape social definitions that govern social action (Altheide, 2002). By framing the news stories in the aforementioned manner, Xinwen Lianbo was able to disseminate an anti-outside world rhetoric to millions of its viewers on a daily basis.

Many smaller and less powerful countries, however, occupied the newscast more frequently than the "known" countries. In a sense, coverage of affairs in 
the Middle East was significant in the construction of the chaotic and dangerous outside world frame. It is true that there is chaos there, but there is also positive news and humanitarian efforts that could be reported on. This may explain why Xinwen Lianbo has a tendency to cover stories in Syria, Ukraine, Iraq, even though these three countries are far away from China. The fact that Xinwen Lianbo devoted more stories to disasters/accidents in the United States than in any other region is a way of demonstrating that this world power has weakness. There is no major conflict within the borders of the United States as in Iraq or Syria. Therefore, the decision to focus on disasters, accidents, and scandals in reporting about the country is another way of framing the country as unsafe and tumultuous.

\section{Conclusion}

As noted earlier white propaganda comes from an identified source, presenting information that is correct, and that portrays the sender as the "good guy." To frame is to lead the audience to draw conclusions that the creator of the content, in this case news reports ordered in a particular way by the newscast producers, desires. The fact that the United States has disasters, both man-made and natural, is true, but it means little unless, as in the case of Xinwen Lianbo, it is part of an overall view of the world as chaotic and unstable. All of the wars, disasters (both man-made and natural), scandals, and crime, stand in stark contrast to the positive and "normal" picture painted of China and its leaders. It is, as Jowett and O’Donnell (2006) note, "Propaganda as journalism...to understand how news management or 'spin' shapes information, emphasizing positive features and downplaying negative ones, casting institutions in a favorable light" (p. 1).

Future research could focus on where young people in China are getting their information from as they are a part of the audience that no longer watches Xinwen Lianbo (Huang, 2014). Is the Chinese government using other media sources to send similar negative messages of the world to young people? Conducting surveys in China is extremely difficult, but it would be interesting to know what people who watch Xinwen Lianbo regularly, particularly those in rural areas with less access to information, think of the world. Also, future research should include clearer descriptions of not just what is being presented to Xinwen Lianbo's audience, but how it is being presented in terms of the complete narrative including images used in the stories and the anchor and reporter text.

George Creel (1941) once wrote, "Propaganda-the fight for the promotion and maintenance of morale-can have no other basis than honesty and candor, for in every human being there is an instinct for truth" (p. 340). He was writing as World War II was unfolding, and in the current case of China the battle is not for morale, but control of the whole being. The Chinese government and the producers of Xinwen Lianbo may argue that portraying the world as a scary and dangerous place is the truth, but it is not the whole truth. One can only speculate how many people viewing Xinwen Lianbo have that instinct for truth and wonder if what they are seeing and hearing is completely true. 


\section{References}

Altheide, D. L. (2002). Creating fear: News and the construction of crisis. Transaction Publishers.

Chang, T. K., \& Chen, Y. (2000). Constructing international spectacle on television: CCTV news and China's window on the world, 1992-1996. In A. Malek \& A. P. Kavoori (Ed.), The global dynamics of news: Studies in international news coverage and news agenda (pp. 197-221). Stamford, CT: Ablex Publishing Corporation.

The global dynamics of news: Studies in international news coverage and news agenda, (2), 197.

Chang, J., \& Ren, H. (2015). Television news as political ritual: Xinwen Lianboand China's journalism reform within the party-state's orbit. Journal of Contemporary China, 25(97), 14-24.

Chang, T., Wang, J., \& Chen, Y. (2002). China's window on the world (1st ed.). Cresskill, NJ: Hampton Press.

China's Xi underscores CPC's leadership in news reporting-Xinhua|English.news.cn. (2016). News.xinhuanet.com. Retrieved from https://ces.to/I9Nd12. [Accessed: 10 May 2017]

Chinese telecom exec calls CCTV news critics low class. (2018). Retrieved from https://ces.to/Cqp1s6. [Accessed: 5 May 2019]

Chiricos, T., Eschholz, S., \& Gertz, M. (1997). Crime, news and fear of crime: Toward an identification of audience effects. Social Problems, 44(3), 342-357.

Cody, E. (2007). In a changing China, news show thrives with timeworn ways. The Washington Post. Retrieved from https://ces.to/Nro9Oz. [Accessed: 3 April 2018]

Creel, G. (1941). Propaganda and Morale. The American Journal of Sociology, 47(3), 340-351.

Entman, R. M. (1993), Framing: Toward Clarification of a Fractured Paradigm. Journal of Communication, 43, 51-58.

Entman, R. M. (2007). Framing Bias: Media in the Distribution of Power. Journal of Communication, 57, 163-173.

Fairhurst, G., \& Sarr, R. (1996). The Art of Framing. San Fransisco: Jossey-Bass Publishers.

Gamson, W., \& Modigliani, A. (1989). Media discourse and public opinion on nuclear power: A constructionist approach. American Journal of Sociology, 95(1), 1-37.

Goffman, E. (1974). Frame analysis: An essay on the organization of experience (1st ed., pp. 21-82). Boston: Harvard University Press.

Huang, C. (2014). Retirement of Xinwen Lianbo anchors prompts calls for overhaul of flagship CCTV news bulletin. South China Morning Post. Available from https:// ces.to/6sOJh5.

Huang, H. (2015). Propaganda as Signaling. Comparative Politics, 47(4), 419-437.

ICAO Annex 13 Appendix. (1994). Iprr.org. Retrieved from https://ces.to/sujhjv. [Accessed: 9 May 2017]

Jowett, G. \& O'Donnell, V. (2006). Propaganda and persuasion. Thousand Oaks, CA.: Sage Publications.

Liu, H. (2009). Probability distribution of dependencies based on a chinese dependency treebank. Journal of Quantitative Linguistics, 16(3), 256-273.

Liu, H., Hudson, R., \& Feng, Z. (2009). Using a Chinese treebank to measure dependency distance. Corpus Linguistics and Linguistic Theory, 5(2), 161-174.

Matthes, J., \& Kohring, M. (2008). The content analysis of media frames: Toward 
improving reliability and validity. Journal of Communication, 58(2), 258-279.

McNelly, J., \& Izcaray, F. (1986). International news exposure and images of nations. Journalism \& Mass Communication Quarterly, 63(3), 546-553.

No news is bad news. (2016). The Economist. Retrieved from https://ces.to/GqBOs3.

Olausson, U. (2009). Global warming-global responsibility? Media frames of collective action and scientific certainty. Public Understanding of Science, 18(4), 421-436.

People's Daily. (2014). 央视新闻节目收视高《新闻联播》月收看人次72亿. [online] Media.people.com.cn. Retrieved from https://ces.to/dRWGgy. [Accessed: 11 Nov. 2017]

Pugsley, P., \& Gao, J. (2007). Emerging powers of influence: The rise of the anchor in Chinese television. International Communication Gazette, 69(5), 451-466.

Scheufele, D. (1999), Framing as a theory of media effects. Journal of Communication, 49, 103-122.

Scheufele, D. A., \& Tewksbury, D. (2007). Framing, agenda setting, and priming: the evolution of three media effects models. Journal of Communication, 57: 9-20.

Sterling, C. (2009). Encyclopedia of Journalism (1st ed., pp. 1-236). New York: SAGE Publications.

Sun, W., \& Chio, J. (2012). Mapping media in China (1st ed., p. 105). New York: Routledge.

Szanto, G. (1978). Theater and Propaganda. University of Texas Press.

Terkildsen, N., \& Schnell, F. (1997). How media frames move public opinion: An analysis of the Women's Movement. Political Research Quarterly, 50(4), 879-900.

Tewksbury, D., \& Scheufele, D. A. (2009). News framing theory and research. In J. Bryant, M. B. Oliver (Eds.), Media effects: Advances in theory and research (3rd ed., pp. 17-33). Hillsdale, NJ: Erlbaum.

Tierney, K. (2006). Metaphors matter: Disaster myths, media frames, and their consequences in Hurricane Katrina. The ANNALS of The American Academy of Political and Social Science, 604(1), 57-81.

Tuchman, G. (1978). Making news: A study in the construction of reality. New York: Free Press.

Zhu, Y., \& Berry, C. (2009). TV China. Bloomington, IN: Indiana University Press. 


\section{Appendix}

Accident: Any incident such as traffic accidents (except for an aviation accident), shipwrecks etc.

Aviation accident: According to the International Investigation Standards, an aviation accident refers to "an occurrence associated with the operation of an aircraft which takes place between the time any person boards the aircraft with the intention of flight until such time as all such persons have disembarked" ("ICAO Annex 13 Appendix", 1994). The reason why this category is separated from the "Accident" category is because aviation accidents are rare, but are tragic and high-profile, and therefore have much more social influence.

Crime: Refers to any unlawful act.

Disease: Any story that reports on the cause or effects of disease. For instance, news about the spread of the Ebola virus would be included in this category.

Economic crisis: Refers to a crisis caused by loss of financial assets. The Euro financial crisis is a good example of an economic crisis.

Economics: News events related to banking and economics that are neutrally reported would be labeled "Economics."

Extreme weather: Refers to unpredictable and unusual severe weather, including flooding rain, extreme hot and cold weather.

Gun violence: Violence committed with the use of a deadly weapon.

International conflict: A conflict between different nations or states, involving at least two countries.

Media scandal: Refers to misconduct of media organizations that is detrimental to the public interest. Sexual harassment by prominent media figures, or fabrication of news stories, are included in this category.

Natural disaster: Refers to a natural event that causes great damage or loss of life, such as a flood, earthquake, and hurricane.

Nuclear crisis: Refer to news covering Iran and North Korea's nuclear programs.

Police violence: Refers to excessive force conducted by police officers when handling civilians.

Political affair: Refers to domestic political issues. For instance, News reports such as "Japan Is Moving to Revise Its Pacifist Constitution," "American President Donald Trump fires FBI director James Comey," which deal with political issues in their own country would be considered political affairs. Usually issues related to politics and diplomacy fall into this category.

Political scandal: Refers to misconduct by political agencies or political figures and is considered morally or legally unacceptable.

Racial conflict: Used to describe a conflict between two or more ethnic groups. News stories of Blacks are treated unequally by Whites would be labeled "racial conflict."

Refugee Crisis: Refugees are people from their native country arriving illegally in another country, such as the European Union, to seek asylum.

Social affair: Refers to a social event that is conducted by social group members.

Social unrest: Refers to a large group of people gathering in public to voice demands on issues and fight for those issues. It usually involves rioting. A protest is a typical social unrest.

Sports: Sports news. For example, "Fukushima to Host Baseball in 2020 Tokyo Olympics" is a piece of sports news.

Sports scandal: Refers to disgraceful or discreditable behavior conducted by athletics or sports agencies. Russia's doping scandals and 2015 FIFA corruption case are 
included in this category.

Terrorist attack/terrorism: refers to indiscriminate violence conducted by an individual or an organization to attack civilians and create terror or fear in order to achieve a particular goal.

Warfare: Refers to a war or an activity involved in war.

Other: Refers to the news that cannot be put into the above categories. 
Vol. 5, No. 4 Garfinkle: Simulation, A-signification and Embodied Semiotics... 


\title{
Effects of Anti-Smoking Advertisements on Young People: Role of Gender and Level of Smoking
}

\author{
By Hwiman Chung ${ }^{*}$ \& Euicheol Jung ${ }^{\dagger}$
}

The main argument for using a fear-appeal message is that fear appeal is designed to stimulate anxiety in the audience, with the expectation the audience members will attempt to reduce this anxiety by adopting a specified course of action as suggested in the communication. Among adolescents, negative effect of fear-appeal, which is called "boomerang" effect, has been reported. The present study focused on this "boomerang" effect among young adults. Also, this study tried to test the moderating effect of the level of smoking on this boomerang effect.

Keywords: boomerang effect, fear appeal, moderating effect of smoking.

\section{Introduction}

Although the smoking rate in the world has declined since 1999 from $45 \%$ to $20 \%$ in 2015, most countries have faced a similar problem on smoking - increase of smoking rate in adolescents, college students, and young females (WHO, 2015). Especially, the smoking rate among young people (15-25) has not declined, despite of many anti-smoking campaigns run by the government in many countries.

Most of the campaigns trying to dissuade non-smokers from smoking and to encourage smokers to quit smoking, have used scare tactics (scare people to change their behavior). Although previous studies have shown that fear-appeal advertisements are effective in producing self-protective behaviors across a variety of health issues (Morman, 2000; Roberto, Meyer, Johnson, Atkin, \& Smith, 2002; Witte, 1992), some studies have shown that scare tactics may not work among young people, because young people tend to respond to fear messages differently than adults (Pechmann, Zhao, Goldberg, \& Reibling, 2003). That is, young people tend to feel they are unable to cope with fear-inducing information, because of their limited attention span. Indeed, teens and adolescents may simply choose maladaptive responses, such as denial of the serious problem, because they are incapable of processing the fear appeal messages. Also, studies have shown that negative effects of fear appeal among young people occur when strong fear appeal is used (e.g., Schneider et al., 2001). That is, when the level of fear (or threat) is too high, its impact on adolescents becomes negative. This negative effect (it has been called the boomerang effect) has been reported by some studies in the fear appeal study (Schneider et al., 2001).

Although this boomerang effect has been addressed in fear appeal literatures, results have not been consistent, and the boomerang effect has not been consistently confirmed in studies. Some studies have shown that the boomerang effect occurs only when the fear appeal is low or moderate, not high (Lennon,

${ }^{*}$ Professor \& Head, Journalism and Media Studies Department, New Mexico State University, USA. ${ }^{\dagger}$ Associate Professor, Seinan-Gakuin University, Fukuoka, Japan. 
Rentfro, \& O'Leary, 2010). However, other studies have shown that the effects of the fear appeal message on adolescents are linear (Ferguson \& Phau, 2013), which tells us that there is no boomerang effect at all. In addition to these contradictory results, another main issue in anti-smoking literature is that there are not many studies addressing this boomerang effect on young people, considering that the smoking rate increases only among young people.

This study has two main goals; first, to empirically test whether the negative effect of fear appeal (boomerang effect) really occurs among young people, and second, to test whether personal differences (gender and level of smoking) have a moderating effect on message acceptance. Through this empirical test, we believe this study can provide a solid explanation on the fear appeal effect on young people in fear appeal literature.

\section{Literature Review}

\section{Fear Appeal}

Fear is an affective state that protects us against danger and a motivational state leading us away from danger. Communications using fear appeal are designed to stimulate anxiety in the audience, with the expectation that the audience members will attempt to reduce this anxiety by adopting, continuing, discontinuing, or avoiding a specified course of thought or action as suggested in the communication (Spence \& Moinpour, 1972). In most communication researches, negative fear appeals (addressing negative effect of certain behavior, such as smoking) have proven to be more effective in certain situations than their positive appeal counterparts. For example, Robberson and Rogers (1988) found that those who read disease-prevention messages containing negative effect indicated greater intentions to begin a regular program of exercise than those who had received health enhancement, or positive appeal, messages. In terms of the persuasive effects of fear appeals, scholars typically have believed that moderate fear appeals are more persuasive than either weak or strong fear appeals. This is because weak appeals create too little tension or drive to action, and strong appeals create too much tension or drive to action. Janis and Feshbach (1953) proposed a curvilinear theory on the persuasive effects of fear appeals. He proposed that the relationship between fear and persuasion is an inverted U-shaped curve, indicating that moderate fear appeal messages would be optimal for the greatest audience persuasion.

Most of the anti-smoking studies have manipulated the level of threat to determine their effectiveness regarding either attitude or behavior changes (Beck \& Davis, 1978; Leventhal, Watts, \& Pagano, 1967; Rogers \& Mewborn, 1976). For instance, Beck and Davis (1978) manipulated the level of threat and topic relevance for anti-smoking messages on attitude, and Leventhal et al. (1967) manipulated the level of threat of the anti-smoking message on both attitude and behavior. Other popular message types used in fear appeal studies manipulated the level of fear or threat using social risk or personal/physical risk (Laroche, Toffoli, Zhand, \& Pons, 
2001; Murray-Johnson et al., 2001). Rather than manipulating the actual level of fear, these studies manipulated the types of fear, suggesting different potential risks to the message receiver - for example, social fear versus personal fear. Laroche et al.'s study used social fear messages (the threat of the intensity of social rejection) versus physical fear messages (the threat to one's physical body, health and life) to test cultural differences. The reaction to the message differences was compared between subjects from two countries - China and the United States. MurrayJohnson et al. (2001) also tested the effects of different types of fear messages regarding AIDS prevention. In their study, they manipulated fear-inducing messages using self-threatening messages versus family threatening messages. Their results were similar to those of the Laroche et al. study. They found that family threatening messages were more effective for teens in collectivistic culture (Mexican immigrants in their study), and self-threatening messages were more effective for teens in individualistic cultures.

\section{Level of Smoking on Severity of Threat and Probability of Threat}

Personality difference has been explored in many different disciplines. In general, it is agreed among scholars that personality difference moderates the effect of a persuasive message (e.g., Petty and Cacioppo's Need for Cognition in persuasive message process). Those personal variations include cognitive aspects, such as level of personal involvement, level of personal knowledge, need for cognition, to affective aspects such as emotion or attitude. In the area of fear appeal, however, the effects of personal variations or difference on message acceptance or behavior change have been extremely rare, since most scholars have focused on cognitive aspects of the message processing of fear appeal advertisement. Schoenbachler and Wittler (1996) tested the impact of sensation seeking (defined as individual's varying need for arousal) on the process of fear appeal anti-smoking ads among adolescents. Because they were interested in the subject's emotional responses in the process of fear appeal messages, they tested the role of varying need for arousal. More recently, Morman (2000) tested the effects of level of masculinity on performing the testicular self-exam. He found that the more a man approves of the traditional masculine gender role, the less positive his attitudes are toward performing the testicular self-exam.

\section{Smoking and Self-Image}

Most people perceive themselves in terms of the role, or roles, they play. Much of their behavior consists of acts designed to demonstrate to others and to themselves that they really carry out the demands of their roles. People structure their actions and statements in order to guide the impression they want to form of themselves. In sociology, cigarette smoking is considered a very important symbolic behavior and an important source of role definition (Starr, 1984). In particular, cigarette smoking among young people has a symbolic meaning of "quasi-adult" behavior, and smoking cigarettes has the image of masculinity to the 
young smokers (Starr, 1984). Most of the communication scholars agree that mass media has played an important role in creating a masculine image of smoking cigarettes (Starr, 1984). In American society, cigars and cigarettes have become an accepted accouterment of a masculine man and smoking has long been part of the masculine self-concept (Starr, 1984).

In anti-smoking fear appeal literature, it is agreed among scholars that smokers are different from non-smokers, heavy smokers are different from light smokers, male smokers are different from female smokers (Pflaum, 1965). For instance, smokers are more likely to be characterized as being extroverted, thrillseeking, independent, and energetic (Pflaum, 1965). In contrast, non-smokers are characterized as being stable, dependable, religious, and conservative. Furthermore, male smokers tend to be less masculine (Fisher, 1976), and female smokers tend to be more masculine and independent (Fisher, 1976). These personality differences suggest a possible moderating effect of personality on evaluating threat in the process of fear-appeal message. That is, we can infer that smokers (since they are more likely to be thrill-seeking) will evaluate the threat by fear-appeal messages less than non-smokers, and the same to the probability of threat. Smokers, these days, are considered as lower class people and lower educated people (Starr, 1984).

However, this personal difference has not been directly tested in anti-smoking fear appeal context. Recently, Chung and Ahn (2016) tested the level of smoking in their test of structural model, based on Extended Parallel Process Model (EPPM). Their findings partially supported the possible moderating effects of personal difference in the process of anti-smoking fear appeal. However, because not all of the hypotheses were supported in their study, we cannot empirically conclude that the level of smoking will moderate the effects of anti-smoking ads.

Few studies in fear appeal literature have shown the relationship between the degree of smoking experience and the process of coping responses. Some studies have shown that message acceptance would be different by a person's level of experience (e.g., smoking, drug, alcohol etc). Schoenbachler and Whittler (1996) and Morman (2000) found that the fear appeal message was more effective (accepted) to people who had a lower level of drug experience than a higher level of experience. That is, people with less experience with drugs, alcohol, or smoking are more likely to accept the fear appeal message and are more willing to accept the message (quitting drugs, alcohol, or smoking) than people with more experience with drug, alcohol, or smoking (Schoenbachler \& Whittler, 1996). Therefore, it will be reasonable to assume that the relationship between the level of smoking (or degree of smoking) and process of coping responses, such as threat appraisal of the fear appeal message and perceived fear of anti-smoking ads, will be different, depending on an individual's level of smoking experience. Further, selecting responses to anti-smoking advertisements would be different by an individual's degree of smoking. For example, if an individual smoked in the past, he or she may be tempted to repeat the experience, when the third party offers a cigarette in a social occasion. 


\section{Theoretical Background}

Smoking has been promoted as a tool of showing a person's masculinity and macho image in mass media including movies (Starr, 1984). Hence, smoking becomes more of a man's thing instead of a woman's thing. As Hunt, Hannah, and West (2004) found, the masculinity score was much higher for smokers (male and female smokers) than non-smokers. The theory of psychological reactance (Brehm, 1966) supports the above argument why fearful anti-smoking ads do not work for high-masculine smokers (heavy smoker vs. medium smoker vs. light smoker vs. non-smoker). According to Brehm (1966), messages that are perceived to reduce or threaten personal freedoms (in this case, decide to smoke or keep smoking) arouse a motivational state (in other word, reactance) which directs individuals toward re-establishing the loss of threatened freedom. Bensley and Wu (1991) showed the reactance effects among college undergraduate students using alcohol drinks (beer). That is, undergraduates actually rated high-threat ads more negatively than low-threat ads, and, eventually, undergraduate students consumed more beer after exposure to high-threat ads than to low-threat ads. Hence, exposure to highthreat ads actually created the opposite behavior. Since threatened or eliminated freedoms seem more attractive to young people, behaviors prohibited or perceived to be off limits for certain audiences are more attractive to audience members to whom the restriction applies. For instance, one study found that simple warning labels outside video tapes have shown to make violent movies more appealing to young age groups (Bushman \& Stack, 1996). Further, these young age groups showed more attraction to the films with the warning labels by US Surgeon General.

If young people respond differently to fear appeal anti-smoking ads, we can expect that level of smoking may work as a moderator in the process of anti-smoking ads. That is, we can expect different responses on anti-smoking ads by subjects' level of smoking. Based on the results of the previous studies, we can also expect that anti-smoking ads will work negatively among highsmokers, because high-smokers will show greater masculinity (Hunt et al., 2004). So, in this study, we expect high-smokers to have a negative emotional response and a negative message acceptance to the fear-appeal ads than the nonsmokers.

\section{Research Questions and Hypotheses}

For this study, we try to answer the following questions and hypotheses that were developed based on previous studies and theories. Overall, the research question is on whether there are negative effects of fear appeal ads on young people. Because the results on negative effects have been contradictory, we try to empirically re-test this effect by using three different levels of fear. Another research question is on whether the level of smoking has a negative impact on processing the message. We expect negative impact by level of smoking on emotional response and cognitive response, based on the results of previous studies on personality difference. Hence, the following hypotheses were tested for this study: 
H1: Overall, among young people, fear appeal will not work positively.

H2: The effects of fear appeal, measured as an emotional response, risk perception and behavioral intention, will be different by gender. Fear appeal will not work positively among male subjects.

H3: There will be negative effects of fear appeal, among subjects. That is, the effects of fear appeal to young people will be reduced as fear appeal becomes higher.

H4: The level of smoking will negatively affect the severity of threat and probability of threat.

H5: Difference in smoking will negatively affect a person's emotional response (fear arousal).

\section{Method}

\section{Overview}

This study was conducted in Japan in October through December, 2017, at a private university in Fukuoka, Japan. Japan was selected to test the fear appeal anti-smoking ads for several reasons. First, the Japanese government has never run an anti-smoking campaign targeting young people. Hence, young people have no knowledge on anti-smoking ads. Second, the smoking environment and smoking culture is much different from those of other developed countries. Although the adult smoking population decreased overall during the 1990's and 2010's from $56 \%$ to $19 \%$ (Japan Health Net, 2017), male smoking is still over 31\%, which is more than the world average of 20\% (Japan Health Net, 2017). Especially, in adolescents and young adults, the smoking rate in Japan is still strong and consistent (young males at $31 \%$ and young females at 10\%). Although Japan has strong regulations over the legal smoking age (for example, the legal age for smoking is over 20 years old in Japan, compared to 18 in the USA), the culture of smoking in Japan is very different from that of other developed countries. Unlike in Europe and North America, where mandatory smoking bans apply in restaurants, bars, and public areas; smoking in public places, such as a restaurant, park, or buildings, in Japan is not illegal yet. In addition to this, the decline rate among young people is not as fast as that of old people. Some studies show there is no actual decrease in smoking among adolescents and young college students, especially among female adolescents and college students. And finally, Japanese is said to be a collectivistic culture (Ho, 1998), in which peer or group pressure is much greater than in an individualistic culture. If a group is generous to smoking, then, people may process anti-smoking messages differently than people in an individualistic culture. We administered a quasi-experiment during those time periods.

\section{Stimulus Materials}

To maximize the chances of obtaining a real fear effect, unlike previous 
studies, this study used actual advertisements, through online searches for antismoking campaigns in the world. Great care was given to select an advertisement the subjects would not have likely seen previously (most of the anti-smoking ads on the internet in Japan were excluded and this was validated through a pilot test using a five 7-scale semantic differential questions). Advertisements were first screened by this criterion, and then rated by twenty undergraduate students in terms of degree of fear. Three advertisements from high level of fear (average 5.86), medium level of fear (average 4.62), and one from low level of fear (average 2.43) were selected based on the students' rating (because we needed to have all different levels of ads, we used t-statistic to test the difference between each level). Visuals from those selected ads were used for this study, and message types were manipulated in the body copies. To manipulate high-fear, medium-fear and low-fear, this study focused on manipulating threat and severity. In the theory of motivation protection (Rogers \& Mewborn, 1976; Rogers, 1983), fear-appeal can consist of fear, threat and efficacy. Most of the studies have manipulated threat as a main tool to create the mood of fear. This study also manipulated the threat of smoking to smokers' health to create fearappeal.

The stimuli consisted of two parts: (1) two photographs (in the upper half), and (2) textual messages (in the lower half). On the upper left side, one photo shows a smiling healthy young man, which corresponds to the original situation before smoking. On the upper right side, the other photo shows the same person with advanced skin cancer due to his long time smoking, which corresponds to the disease-and-suffering situation. We manipulated the latter picture of the cancer patient. For the high fear-provoking advertisement, a color photo with a severely deteriorated tumor on his neck was used. For the medium-fear ad, we used a color photo with severely damaged smoker's teeth, and for the low-fear ad, a color photo with a patient in bed with several tubes was used. These pictures were rated as high, medium, and low by students in the pilot test.

For high fear, headlines and body copies addressed the issues of 5 different diseases, illnesses, and other effects caused by smoking cigarettes. Headlines warned that death could result by those who smoked cigarettes: "Smoking, Shortcut to Fast Death." In the body copy, the actual person's name, who is suffering from many cancers caused by smoking cigarettes for a long time, was used. And, in another body copy, all the possible diseases caused by smoking were listed, with the indication of high death rate. All the information in the message was accurate, and to increase the credibility of the message, a third party (such as Japan Cancer Society) was quoted in the body copies. For medium-fear, the same headlines as in the high-fear were used. Sub headlines were changed from 6 months left to "he has problems inside his mouth and teeth". In the body copies, the number of diseases caused by smoking was reduced to 2 and the indication of high death rate was removed. Finally, for the low-fear, headlines and sub-head were rewritten from direct death message to indirect message, such as "Quit smoking to live longer." Also, in the body copy, all diseases were removed and just the possibility by smoking was addressed. 


\section{Procedures}

The samples consisted of undergraduate students at a major private university in Japan. Data were collected from several different majors (business administration, management, English, English literature, etc.) to increase the diversity of the sample. After obtaining a complete list of the program curricula, the courses were randomly split into three groups, each of which was assigned the high, medium, or low fear-provoking stimuli. With prior permission from the instructors, researchers visited classes and students were told that the researchers were conducting a preliminary study to develop an effective campaign for Japan's first anti-smoking legislation. This was used to keep the students' involvement level constant. Students were completely unaware of the study purposes. No incentives were given. Then, each group of students was shown the respective advertisement and asked to complete the questionnaire after exposure.

\section{Dependent Measures}

Degree of fear, message acceptance, health risk perceptions, attitude toward the advertisement, attitude toward smoking, and behavioral intention were all measured. Most variables were measured with a seven-point Likert scale, or seven-point semantic differential scale, where "1" equals strongly disagree" and "7" equals "strongly agree." Items representing the same construct were averaged to create an index score. Those items measured include:

1. Manipulation Checks. Perceived fear was measured with five sevenpoint Likert scales (in the pilot test, the same scales were used to select advertisements): fearful, worried, frightened, anxious, scared $(\alpha=.93)$ (Chug \& Ahn, 2016; Laroche et al., 2001).

2. Attitude toward the Advertisement. A multi-item, seven-point semantic differential scale that was used to measure attitude toward the advertisement in several fear message studies was also used to measure attitudes toward the anti-smoking advertisements (e.g., Schoenbachler \& Whittler, 1996). These include the following anchors: Bad-Good, Unpleasant-Pleasant, Useless-Useful, Worthless-Valuable, Not BeneficialBeneficial $(\alpha=.75)$.

3. Attitude toward Smoking. This was measured using a multi-item sevenpoint Likert-type scale, where "1" equals negative values (very undesirable, very unfavorable, not at all beneficial) and "7" equals positive values (very desirable, very favorable, very beneficial). Negative values were later reverse-coded $(\alpha=.83)$.

4. Behavioral Intention. Behavioral intentions to quit smoking were measured through two seven-point Likert-type questions, which were adopted from Murray-Johnson et al.'s study, with "1" indicating "strongly disagree" through "7" indicating "strongly agree" (e.g., "I plan to quit smoking soon" and "I plan to stop people from smoking") $(\alpha=.90)$.

5. Risk Perceptions. Perceived severity of the health risks of smoking was 
measured in the same way used in the Pechmann et al.'s study. We selected five items which focused on disease and death from the nine items used in that study: dying early, contracting diseases, breathing poisons, premature aging, and causing others to die or become ill. Subjects were asked to mark each outcome as "very serious" or "not at all serious" ( $\alpha=.61)$.

\section{Results}

Data collected were analyzed first in terms of univariate descriptive statistics and multivariate normality. The data was satisfactory in terms of univariate descriptive statistics, for there was no case outside of $+/-3$ standard deviations, and specific univariate outlying cases were not found in univariate descriptive statistics. A manipulation check was conducted for "fear." After the manipulation check, ANOVA was conducted to test the suggested hypotheses.

\section{Descriptive Statistics}

A total of 216 subjects completed the study. They ranged in age from 18 to 25 and the average age was 20 with a 2.05 standard deviation. 125 participants were females and 91 were males. As expected, they represented a wide variety of academic majors. $68.8 \%$ were non-smokers and $31.1 \%$ were smokers, and this rate was a little bit higher than national average $29 \%$. The percentage of male smokers was $52.8 \%$ and of female smokers was $15.3 \%$. Both were higher than the national average. Among smokers, $13.2 \%$ identified themselves as heavy-smokers, $50 \%$ as moderate-smokers and $36.8 \%$ said they were light-smokers.

\section{Manipulation Checks}

The manipulation was checked for perceived fear and threat severity. Because this study used both visual and message to manipulate fear in different levels, we used perceived fear to check the overall fear levels and threat severity to check the message manipulations. Our results confirmed the manipulations for overall fear were effective. Participants in a high-fear manipulation $(M=5.32, S D=1.06)$ showed greater perceived-fear than participants in medium-fear $(M=4.34, S D=1.36)$ and in a low-fear manipulation $(M=2.66, S D=1.09)(F=83.32, p<.01)$. Results on threat severity also confirmed our manipulation on the message worked. Participants in the high-threat showed the highest threat severity evaluations $(M=4.97, S D=1.32)$ than those participants in the medium-threat $(M=4.29, S D=1.51)$ and those participants in the low-threat $(M=2.27, S D=.99)$. And the difference among groups was significant $(F=74.23, p<.01)$.

\section{Hypothesis 1 - Fear Effects}

In fear appeal literature, the effect of fear appeal on message acceptance was not consistent. As stated above, some scholars support the linear effect of fear 
appeal and others support the so called, boomerang effect. In this study, we argued that strong fear appeal will not create a linearly positive impact on message acceptance. To test the first hypothesis, we used three variables - attitude toward the ad, attitude toward smoking, and behavioral intention. On attitude toward the ad, results show that participants prefer medium-fear appeal and message. Mean scores on attitude toward ad was highest among participants in medium-fear $(M=4.91, S D=.83)$, followed by low-fear $(M=3.97, S D=1.05)$ and high-fear $(M=3.24, S D=.97)$. The difference was statistically significant $[F(2,213)=104.29$, $p<.01]$.

On the attitude toward smoking, results show participants in the medium-fear showed the highest means scores on attitude toward smoking. Mean scores was highest among participants in the medium-fear $(M=4.14, S D=.81)$, followed by low-fear $(M=4.07, S D=1.17)$ and high-fear $(M=3.67, S D=1.12)$. The difference was statistically significant $[F(2,213)=5.42, p<.01]$. However, unlike the attitude toward the ad, the difference between the medium-fear and the low-fear was not significant, which means participants actually think that the medium-fear and the low-fear messages are more effective on persuasion.

On behavioral intention, results show that no significant difference among groups exists on intention to quit. Mean scores of each group was not significantly different and ANOVA test did not show any difference among groups.

Therefore, hypothesis 1 was not fully supported. However, regarding the attitude toward the ad and the attitude toward smoking, results confirm our expectation that fear appeal effect is not linear among young people.

\section{Hypotheses 2 - Gender Difference}

The second hypothesis expects the difference on the message acceptance by gender. As tested in previous studies, response to the fear message was different between male and female. We, in this study, also expect that the response to the strong fearful message will be different by gender. To test the hypothesis, a mean difference test (t-test) was conducted on overall dependent measures. The results show that there are significant differences between genders on intention to quit and attitude toward smoking. As we expected, females show a higher intention to quit and a lower attitude toward smoking. However, regarding perceived fear and threat severity, there was no significant difference between genders. Although mean scores are a little higher for females on both measures, the differences were not statistically significant. Therefore, hypothesis 2 was not supported by the data. Unlike our expectations, there was no difference between gender on perceived fear and threat severity. One interesting finding is that females showed higher mean scores on response efficacy, but lower mean scores on self-efficacy measurements. This shows that the fearful message actually increases females' response to the message, but they do not feel as they are able to do (quitting smoking in this case). In other words, males have high self-efficacy, but are not persuaded as much as females by the fearful message. 


\section{Hypothesis 3 - Boomerang Effect}

Hypothesis 3 states the "boomerang" effect or "inverted-U curve" effect of the fear message. To test this hypothesis, we used three dependent measures intention to quit, attitude toward smoking and attitude toward the ad.

ANOVA was conducted on all three measures. Results showed partial support for the hypothesis. Regarding attitude toward the ad, subjects in the medium fear showed the highest mean score $(M=4.91, S D=.82)$, followed by low-fear $(M=3.98$, $S D=.51)$ and high-fear $(M=3.24, S D=.76)$. The difference was statistically significant $[F(2,213)=104.77, p<.01]$. Also, attitude toward smoking results showed the similar pattern. That is, subjects in the medium fear showed the highest mean score $(M=4.18, S D=.81)$, followed by low-fear $(M=4.06, S D=1.10)$ and high-fear $(M=3.67, S D=1.11)$. The difference was also statistically significant $[F(2,213)=5.42, p<.05]$. However, regarding behavioral intention, the difference among groups was not statistically significant $[F(2,213)=2.28, p>.106]$. Group comparison shows that, on the attitude toward the ad, the differences among all three groups were significant. Regarding the attitude toward smoking, the difference between medium-fear and high-fear was significant, but the differences between low and medium and between low and high were not significant. Regarding behavioral intention, there was no significant difference among all group comparisons.

These results show very important implications. That is, the medium fear message will be more persuasive to young people than the high-fear message.

\section{Hypothesis 4 and 5 - Moderating Effect of Level of Smoking to Fear Message}

Hypothesis 4 and 5 expect the moderating effect of the level of smoking on the fearful message. In previous studies (e.g., Chung \& Ahn, 2016), the level of smoking has been tested as a moderating variable on the effects of the fear appeal message. However, those results were not consistent in overall fear appeal literature. In this study, we re-tested the effects of the person's level of smoking on message acceptance and emotional response. As in the previous studies, we expected the effects of a fearful message on message acceptance and on a person's emotional response to be different between smokers and non-smokers. For this study, we also tested the difference between heavy smokers and light/medium smokers. Because there is no clear distinction in the definition of heavy-, medium, and light-smokers, we, in this study, used self-identification through giving smokers a choice of heavy- or medium/light-smoker in the question.

First, we ran a t-test to see the difference between smokers and non-smokers. For this test, those who identified themselves as either heavy or medium/light smokers, were re-coded as smokers. The results show that between smokers and non-smokers, there were significant differences between groups on most of the dependent measures, except the attitude toward the ad. Table 1 shows the means for each group and the results of the t-test between groups. As you see in the table, mean differences on most of dependent measures were significant, except the attitude toward the ad. This was a little different result, since we expected the 
difference on attitude toward the ad by smoking.

Table 1. Results of the t-tests on Dependent Variables

\begin{tabular}{|c|c|c|c|c|}
\hline Dependent Measures & Groups & Mean (SD) & $\mathbf{t}$ & $\mathbf{p}$ \\
\hline \multirow{2}{*}{ Perceived Fear } & Non-smokers & $4.41(1.50)$ & \multirow{2}{*}{2.51} & \multirow{2}{*}{.013} \\
\hline & Smokers & $3.81(1.74)$ & & \\
\hline \multirow{2}{*}{ Threat Severity } & Non-smokers & $4.17(1.61)$ & \multirow{2}{*}{2.54} & \multirow{2}{*}{011} \\
\hline & Smokers & $3.54(1.83)$ & & \\
\hline \multirow{2}{*}{ Attitude toward smoking } & Non-smokers & $4.03(1.01)$ & \multirow{2}{*}{4.05} & \multirow{2}{*}{.000} \\
\hline & Smokers & $3.46(.75)$ & & \\
\hline \multirow{2}{*}{ Behavioral Intention } & Non-smokers & $5.08(.65)$ & \multirow{2}{*}{6.18} & \multirow{2}{*}{.000} \\
\hline & Smokers & $4.38(.99)$ & & \\
\hline
\end{tabular}

Second, after t-test, we ran One-Way ANOVA to test smoking main effect, and then, we also ran group comparisons to see where the differences are coming from. The group comparison was mainly used to see whether there is any boomerang effect by the level of smoking. Table 2 shows mean scores of each level and F-test statistics. As seen in the table, there were significant differences among groups on dependent measures. However, most of the differences were coming from the difference between non-smokers and smokers, not between heavy-smokers and light-smokers, except the behavioral intention. Although there were mean differences between heavy- and light-smokers, those differences were not statistically significant. On threat severity and occurrence probability, the overall difference was significant, but there was no difference between each group. Therefore, the boomerang effect was not confirmed on the subjects' risk perceptions - threat severity and occurrence probability.

Table 2. Mean Scores of Each Level

\begin{tabular}{|c|c|c|c|c|}
\hline Dependent Measures & Groups & Mean (SD) & $F(2,212)$ & $\mathbf{p}$ \\
\hline \multirow{3}{*}{ Perceived Fear } & Non-smokers & $4.41(1.50)$ & \multirow{3}{*}{3.65} & \multirow{3}{*}{.028} \\
\hline & Heavy-smokers & $3.67(1.68)$ & & \\
\hline & Light-smokers & $4.10(1.86)$ & & \\
\hline \multirow{3}{*}{ Threat Severity } & Non-smokers & $4.17(1.61)$ & \multirow{3}{*}{3.21} & \multirow{3}{*}{.041} \\
\hline & Heavy-smokers & $3.51(1.87)$ & & \\
\hline & Light-smokers & $3.57(1.77)$ & & \\
\hline \multirow{3}{*}{ Occurrence Probability } & Non-smokers & $4.67(1.67)$ & \multirow{3}{*}{4.61} & \multirow{3}{*}{.011} \\
\hline & Heavy-smokers & $4.40(1.05)$ & & \\
\hline & Light-smokers & $3.94(.81)$ & & \\
\hline \multirow{3}{*}{ Attitude toward the Ad } & Non-smokers & $4.02(1.01)$ & \multirow{3}{*}{3.09} & \multirow{3}{*}{.047} \\
\hline & Heavy-smokers & $4.23(1.11)$ & & \\
\hline & Light-smokers & $3.59(.63)$ & & \\
\hline \multirow{3}{*}{ Attitude toward Smoking } & Non-smokers & $4.03(1.01)$ & \multirow{3}{*}{8.79} & \multirow{3}{*}{.000} \\
\hline & Heavy-smokers & $3.38(.67)$ & & \\
\hline & Light-smokers & $3.65(.89)$ & & \\
\hline \multirow{3}{*}{ Behavioral Intention } & Non-smokers & $6.34(.91)$ & \multirow{3}{*}{85.96} & \multirow{3}{*}{.000} \\
\hline & Heavy-smokers & $3.45(1.49)$ & & \\
\hline & Light-smokers & $4.59(1.24)$ & & \\
\hline
\end{tabular}


As stated above, the boomerang effect by mean difference was confirmed on perceived fear, attitude toward smoking, and behavioral intention. However, the difference came from the difference between non-smokers and smokers, not between heavy-smokers and light-smokers. Only on behavioral intention, was there a significant difference between heavy and light smokers.

\section{Conclusion}

Although a large body of fear appeal research has found that fear stimulates an individual's action, the effects of anti-smoking advertisements using fear appeal on message acceptance or on action have been inconsistent. Some studies have shown that fear appeal anti-smoking advertisements have a positive influence on smokers (Ho, 1998) and on teenagers (Pechmann et al., 2003), while other studies have reported that anti-smoking advertisements have no influence on smokers (Kothe \& Mullan, 2011). Furthermore, there have not been many studies regarding the negative effects of strong fear appeal on the message acceptance.

This study initially addressed the effects of fear appeal on message acceptance. However, the main goal of this study is on testing the boomerang effects of fear appeal. As indicated above, there are some scholars who are arguing the negative effects of using strong fear appeal on subjects' message acceptance. This study is the first attempt to try to manipulate the fear appeal into three levels high, medium, low - to test whether the effects of a fear appeal message are linear or whether a boomerang effect exists. This study also tried to test the impact on the level of smoking. As in the recent studies by Chung and Ahn (2016) and Chung, Okazaki, and Ha (2004), this study also tried to test the moderating impact of a subject's level of smoking. Chung and Ahn argued that the effect of the fear appeal message is not working, as intended, to smokers. They found in their studies that the level of smoking negatively affects the subject's message acceptance. However, the effects of smoking on the message acceptance were not directly tested in their studies. Therefore, this study was the first attempt to empirically test the effects of a person's level of smoking on the fear appeal message.

Of the five hypotheses we suggested, only two of them were fully supported by the data. The other hypotheses tested in this study were partially supported or not supported at all. First, results confirmed that there was a negative effect by a strong fear appeal message. On attitude toward the ad and smoking, results show that participants prefer medium- or light-fear appeal message over the high-fear appeal message. However, on behavioral intention, this study did not find significant difference among the high-, medium-, and light-fear appeal message. Also, there was no significant difference between the medium- and low-fear appeals on emotional response; which means that subjects perceived only the strong fear appeal negatively.

Second, the results show there are significant differences between genders on the intention to quit and the attitude toward smoking. Female subjects show a higher intention to quit and a lower attitude toward smoking. However, unlike our 
expectation, there was no significant difference between males and females on emotional responses, perceived fear. One interesting finding is that females showed higher mean scores on response efficacy, but lower mean scores on selfefficacy measurements. This shows that a fearful message actually increases a females' response to the message, but they do not feel as they are able to do (quitting smoking in this case). In other words, males have a higher self-efficacy than females, but they are not persuaded as much as females by the fearful message.

Third, results showed partial support for the 'boomerang' effects of using a strong fear appeal message. Subjects in the medium fear showed the highest mean score on attitude scores, followed by low- and strong-fear appeal. Group comparison shows that the difference between medium-fear and high-fear was significant, but the differences between low-fear and medium-fear and between low-fear and high-fear were not significant. However, this boomerang effect didn't exist on behavioral intention. These results show very important implications. That is, a medium fear message will be the most persuasive to young people.

Finally, the results show that there was a significant difference between smokers and non-smokers. However, most of the differences were coming from the difference between non-smokers and smokers, not between heavy-smokers and light-/medium-smokers. Although there were mean differences between heavyand light-/medium-smokers, those differences were not statistically different. Therefore, the boomerang effect was not confirmed on the subjects' risk perceptions - threat severity and occurrence probability.

\section{Discussion and Practical Implication}

Previous research has focused on different effects of the level of fear used in the anti-smoking advertisements on message acceptance. This study attempted to test the effect of anti-smoking advertisements using fear-appeal. In particular, this study attempted to test whether there is a negative effect by the level of fear appeal. The primary purpose of the study was to test whether the boomerang effect exists among young college students and whether the level of smoking works as a moderating variable in the success of anti-smoking advertisements. As noted above, the fear-arousing anti-smoking advertisement (high-fear) works better for enhancing message acceptance (to quit smoking or consider quitting) than the lowfear advertisement. However, the results also confirmed that negative effects of fear appeal exist among college students. Although there was no significant difference on behavioral intention, young smokers actually prefer a medium-level fear appeal message, followed by low-fear. A high-fear message has the lowest attitude scores among young people. Also, the results show that there are significant differences between genders on the intention to quit and the attitude toward smoking. As the results showed, females showed higher mean scores on response efficacy, but lower mean scores on self-efficacy measurements. This shows that the fearful message actually increases the females' response to the message, but they do not feel as they are able to do (quitting smoking in this case). In other words, males have high self-efficacy, but are not persuaded as much as 
females by the fearful message. Also, the results confirmed that there exists the so called boomerang effect (negative response to high-fear message) among young people. However, most of the differences came from the difference between nonsmokers and smokers, not between heavy-smokers and light-smokers.

The most important findings of this study confirm the fact that there might be a boomerang effect on the fear appeal messages. Because of this finding, we wonder how we can avoid this boomerang effect, especially targeting young people. The remaining question on this effect is how we can create the right message and the right level of fear appeal. As seen in the results, young people do not like to see high fear appeal (also young people generated a strong counterargument against the message when they see a high-fear message. This result is not reported in this study). Therefore, when we target young people using a fearful message, we have to figure out what level of fear appeal is right for young people. Also, young people do not like to see the light-fear appeal message, which means it will be very difficult for the message creator to use a right level of fear in the message. Traditionally, the main goal of using fear appeal is to scare people to persuade their behavior. And, this has been the main stream of fear appeal literature. However, studies regarding anti-smoking have found that this fear appeal might not work as expected, because of personality differences (e.g., Chung \& Ahn, 2016), gender difference (Fisher, 1976), or level of smoking difference (Pflaum, 1965). As stated in the introduction, the main concerns regarding smoking are on the increasing smoking rate in adolescents and females, and on cigarette companies' targeting young people because of this trend. If young people resist the fear appeal message, reducing the smoking rate using a fearful message might not work as we expect. Therefore, when we target young people to reduce the smoking rate, communication should be developed in a different way, because using a fearful message will simply not work.

\section{Suggestions for Future Study and Study Limitations}

There are several areas that can be further explored on the effects of fear appeal advertising. First, this study was conducted in Japan, which is one of the most collectivistic cultures in the world. Cultural comparison between individualistic and collectivistic cultures has been conducted in anti-smoking literature. However, those studies did not test the boomerang effect directly in their studies. Because this study is done only in a collectivistic culture, we do not know whether this phenomenon exists in an individualistic culture. This area should be addressed in future studies.

Second, in this study, we did not address the very important issue of selfefficacy effects on coping behavior. Research has shown the effects of self-efficacy on individuals' attitudes toward the communication and behavior decisions, and most of the results confirm that providing high efficacy to the message-receivers increase the behavioral reactions suggested in the message. However, this selfefficacy has not been addressed under the boomerang effect. Since self-efficacy judgments are specific to behaviors and the situation in which they occur, it will be very important to see whether the boomerang effect will be different by self- 
efficacy. Hence, future study should explore the effects of self-efficacy on the message acceptance under the concept of the boomerang effect.

Third, we, in this study, used college students. As we know, peer approval among young people is a very important factor, especially on smoking. Many studies have shown that adolescents start smoking because they look for peer approval. In particular, under the collectivistic culture (Japan), the social approval is a very important concept, due to the members' high value on the opinion of others in the group. Therefore, future studies should explore the effects of social approval among peer groups on the message acceptance, especially under the boomerang effect.

This study faced several limitations that may have influenced the findings. First, as stated above, we conducted this experiment in Japan. Because of the characteristics of Japan as a collectivistic culture, this may restrict the results of this study to those countries of individualistic culture. Second, the age range may have been somewhat restricted since we used college students as our subjects. Even though smoking among college students is increasing in Japan, the most increased smoking is on teens and adolescents, instead of college students. Since college students are more aware of its harmful effects than teens and adolescents, results from using college students are somewhat limited. Third, even though we attempted to create the most professional-looking advertisements possible using actual visuals from real anti-smoking advertisements, subjects were suspicious of the purpose of the study since the quality of the advertisements were not at the same level as advertisements in mass media. Finally, we manipulated fear in a unidimensional way. Since there are many different types of fear, future research should address the effects of different types of fear on the message acceptance.

\section{References}

Beck, K. H., \& Davis, C. M. (1978). Effects of fear-arousing communications and topic importance on attitude change. Journal of Social Psychology, 104, 81-95

Bensley, L. S., \& Wu, R. (1991). The role of psychological reactance in drinking following alcohol prevention messages. Journal of Applied Social Psychology, 21(July), 11111124.

Brehm, J. W. (1966), A theory of psychological reactance. New York: Academic Press.

Bushman, B. J., \& Stack, A. D. (1996). Forbidden fruit versus tainted fruit: Effects of warning labels on attraction to television violence. Journal of Experimental Psychology: Applied, 2, 207-226.

Chung, H., \& Ahn, E. (2016). Processing anti-smoking ad among college students: the role of emotional response and level of smoking. Journal of Promotion Management, 22(3), 370-385.

Chung, H., Okazaki, S., \& Ha, B. (2004). Component differences in sex role: A crosscultural comparison. Southwestern Mass Communication Journal, 20(2), 79-94.

Fisher, J. M. (1976). Sex differences in smoking dynamics. Journal of Health and Social Behavior, 17(June), 156-163

Ferguson, G., \& Phau, I. (2013). Adolescent and young adult response to fear appeals in anti-smoking messages. Young Consumers, 14(2), 155-166. 
Ho, R. (1998). The intention to give up smoking: Disease versus social dimensions. Journal of Social Psychology, 138(3), 368-380.

Hunt, K., Hannah, M., \& West, P. (2004). Contextualizing smoking: Masculinity, femininity and class differences in smoking in men and women from three generations in the west of Scotland. Health Education Research, 19(3), 239-249.

Janis, I. L., \& Feshbach, S. (1953). Effects of fear-arousing communication. Journal of Abnormal and Social Psychology, 48(1), 78-92.

Japan Health Net. (2017). Retrieved from https://ces.to/3RYubi. Accessed on November $1,2017$.

Kothe, E. J., \& Mullan, B. A. (2011). Smokers and ex-smokers reaction to anti-smoking advertising: A mixed methods approach. Orbit, 2(1).

Laroche, M., Toffoli, R., Zhang, Q., \& Pons, F. (2001). A cross-cultural study of the persuasive effect of fear-appeal messages in cigarette advertising: China and Canada. International Journal of Advertising, 20(3), 297-317.

Lennon, R., Rentfro, R., \& O'Leary, B. (2010). Social marketing and distracted driving behaviors among young adults: the effectiveness of fear appeals. Academy of Marketing Studies Journal, 14(2), 95-113.

Leventhal, H., Watts, J. C., \& Pagano, F. (1967). Effects of fear and instructions on how to cope with danger. Journal of Personality and Social Psychology, 6(3), 313-321.

Morman, M. T. (2000). The influence of fear-appeals, message design, and masculinity on men's motivation to perform the testicular self-exam. Journal of Applied Communication Research, 28(2), 91-116.

Murray-Johnson, L., Witte, K., Lie, W., Hubbell, A. P., Sampson, J., \& Morrison, K. (2001). Addressing cultural orientation in fear appeals: Promoting AIDS-Protective behaviors among Mexican immigrant and African American adolescents and American and Taiwanese college students. Journal of Health Communication, 6(1), 335-358.

Pechmann, C., Zhao, G., Goldberg, M. E., \& Reibling, E. T. (2003). What to convey in antismoking advertisements for adolescents: The use of protection motivation theory to identify effective message themes. Journal of Marketing, 67(April), 1-18.

Pfaum, J. (1965). Smoking behavior: a critical review of research. Journal of Applied Behavioral Science, 1(2), 195-209.

Robberson, M. R., \& Rogers, R. W. (1988). Beyond fear-appeals: negative and positive persuasive appeals in health and self-esteem. Journal of Applied Social Psychology, 18(3), 277-287.

Roberto, A. J, Meyer, G., Johnson, A. J., Atkin, C. K., \& Smith, P. K. (2002). Promoting gun trigger-lock use: insights and implications from a radio-based health communication intervention. Journal of Applied Communication Research, 30(3), 210-230.

Rogers, R. W. (1983). Cognitive and physiological processes in fear-appeals and attitude change: A revised theory of protection motivation. In J. T. Cacioppo and R. E. Petty (Eds.), Social Psychophysiology: A Sourcebook (pp. 153-176). New York: Guilford.

Rogers, R. W., \& Mewborn, C. R. (1976). Fear-appeals and attitude change: effects of a threat's noxiousness, probability of occurrence, and the efficacy of coping responses. Journal of Personality and Social Psychology, 34(1), 54-61.

Schneider, T. R., Salovey, P., Pallonen, U., Mundorf, N., Smith, N. F., \& Steward, W. T. (2001). Visual and auditory message framing effects on tobacco smoking. Journal of Applied Social Psychology, 31(4), 667-682.

Schoenbachler, D. D., \& Whittler, T. E. (1996). Adolescent processing of social and physical threat communications. Journal of Advertising, 25(4), 37-54.

Spence, H. E., \& Moinpour, R. (1972). Fear-appeals in marketing - A social perspective. 
Journal of Marketing, 36(3), 39-43.

Starr, M. E. (1984). The Marlboro man: cigarette smoking and masculinity in America. Journal of Popular Culture, 17(1), 45-57.

WHO. (2015). Global report on trends in prevalence of tobacco smoking 2015. Available from https://bit.ly/2HMo8SK.

Witte, K. (1992). The role of threat and efficacy in AIDS prevention. International Quarterly of Community Health Education, 12(3), 225-249. 